

\title{
Measuring the Efficiency of Large Pharmaceutical Companies: An Industry Analysis
}

\author{
Fernando Gascón ${ }^{1}$, Jesús Lozano ${ }^{2}$, Borja Ponte ${ }^{2, *}$, and David de la Fuente ${ }^{2}$ \\ ${ }^{1}$ Faculty of Economics and Business, University of Oviedo, Campus del Cristo s/n 33006 Oviedo (Spain) \\ ${ }^{2}$ Polytechnic School of Engineering, University of Oviedo, Campus de Viesques s/n 33204 Gijón (Spain) \\ *corresponding author - email: ponteborja@uniovi.es - telephone number: +34 985182657
}

\begin{abstract}
:
This paper evaluates the relative efficiency of a sample of 37 large pharmaceutical laboratories in the period 2008-2013 using a Data Envelopment Analysis (DEA) approach. We describe in detail the procedure followed to select and construct relevant inputs and outputs that characterize the production and innovation activity of these pharmaceutical firms. Models are estimated with financial information from Datastream, including R\&D investment, and the number of new drugs authorized by the European Medicines Agency (EMA) and the US Food and Drug Administration (FDA) considering the time effect. The relative performances of these firms -taking into consideration the strategic importance of $\mathrm{R} \& \mathrm{D}$ - suggest that the pharmaceutical industry is a highly competitive sector given that there are many laboratories at the efficient frontier and many inefficient laboratories close to this border. Additionally, we use data from S\&P Capital IQ to analyze 2,071 financial transactions announced by our sample of laboratories as an alternative way to gain access to new drugs, and we link these transactions with R\&D investment and DEA efficiency. We find that efficient laboratories make on average more financial transactions, and the relative size of each transaction is larger. However, pharmaceutical companies that simultaneously are more efficient and invest more internally in $R \& D$ announce smaller transactions relative to total assets.
\end{abstract}

\section{Keywords:}

Pharmaceutical laboratories; new chemical entities; business performance; R\&D; market for technology; non-parametric efficiency; DEA

\section{JEL Classification:}

I15, O32, L6, L65

\begin{abstract}
Acknowledgement:
Fernando Gascón would like to acknowledge financing from the Government of Spain through national research project ECO2012-31772. Borja Ponte would like to thank the Government of the Principality of Asturias for financially supporting his work through the Severo Ochoa program (reference BP13011). We also would like to thank professor Laura Cabiedes for her helpful comments and suggestions.
\end{abstract}




\section{Introduction.}

Managing a research and development $(R \& D)$ portfolio of new drugs in the pipeline is a challenging task that involves an active selection and reallocation of resources. In order to be efficient, pharmaceutical laboratories should decide upon strategic issues regarding the laboratory size, internal and external growth options and synergies, and diversity of innovative drugs in each therapeutic area. This decision making should take into consideration the R\&D strategies of their competitors.

In this regard, large pharmaceutical laboratories have two nonexclusive alternatives for managing their portfolio of new drugs in an efficient way. They may develop new drugs internally, but simultaneously they may also engage in mergers and acquisitions (M\&As) - or other financial transactions- to obtain new drugs or to change the composition of their portfolio of promising drugs (sometimes simultaneously selling new drugs and buying other types of new drugs); see figure 1.

PLEASE INSERT FIGURE 1 ABOUT HERE

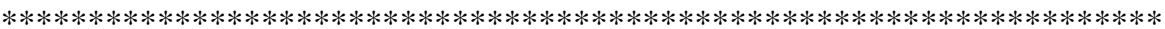

Thus, the market for technology is a way to both acquire and sell knowledge [3] either through collaboration (co-research, co-development or other collaborations), licensing or (and) trough financial transactions. Nishimura and Okada [47] examine how R\&D portfolios of Japanese pharma labs affect licensing decisions (license out and inward licensing). They observe drug pipelines quite accurately due to the rigorous regulatory process of clinical testing. They conclude that drug pipelines may dictate a licensing decision as a result of portfolio adjustment across different stages.

A second alternative to buy (and also sell) knowledge is through financial transactions. In this paper, we measure relative efficiency of pharmaceutical labs and then perform several regressions to test whether efficient labs announce more or less financial transactions than inefficient labs in order to realign their R\&D portfolios.

To the best of our knowledge, regarding the measurement of efficiency of pharma labs, the only contribution similar to this paper is the one by Shimura et al. [52], where large pharmaceutical firms are categorized into four groups (on the basis of their respective R\&D efficiency) and two dimensions (one based on DEA efficiency scores and the other based on effectiveness scores) in order to analyze R\&D productivity. They consider new molecular entities from 21 global pharmaceutical companies in the period 2002-2007 from a database provided by Barclays capital. However, many new drugs in the pipeline do not reach Phase III and some drugs reach it faster than others, so the R\&D activity of a pharmaceutical laboratory is composed of both successful and unsuccessful drugs. These authors account for this by considering R\&D expenditure and net present value.

The DEA efficient frontier in our output-oriented model comprises laboratories that perform better than others. A laboratory in the sample is efficient, given its inputs, if it is not possible to find a linear 
combination of laboratories in the sample having the same inputs and yielding higher outputs. In our case, we use information about successful new drugs from medicines authorized by the EMA and the FDA but in our models we also consider financial information from Datastream, aiming to take into consideration both short-term and long-term indicators of the success of R\&D activity. So, accounting information, market information, and data about new authorized drugs are combined in our DEA efficiency models. In the case of new authorized drugs, we take the time effect into account in a more precise manner. We focus exclusively on DEA efficiency scores, and our objective is to extract as much information as possible from them.

Regarding internal and external R\&D activity, Comanor and Scherer [16] indicate that, in response to lagging innovation, some companies have sought refuge in M\&As. Shimura et al. [52] in their 2002 to 2007 sample, showed that companies with lower R\&D relative to efficiency were more likely to engage in consolidation.

Higgins and Rodriguez [32] focus on the acquisition of knowledge by examining the performance of 160 pharmaceutical acquisitions from 1994 to 2001 and find that on average acquirers realize significant positive returns. These returns are positively correlated with prior acquirer access to information about the $\mathrm{R} \& \mathrm{D}$ activities at target firms and a superior negotiating position. They also find that firms experiencing declines in internal productivity or which are more desperate are more likely to engage in an outsourcingtype acquisition in an effort to replenish their research pipelines.

Girotra et al. [26] indicate that value of an R\&D project depends not only on its properties but also on the other R\&D projects being developed by the pharma lab. They conduct an event study around the failure of phase III clinical trials and their effect on the market valuation of the lab. They find that the presence of other R\&D projects targeting the same market and a build-up of projects that require the same development resources reduce the value of an $R \& D$ project.

Hagedoorn and Wang [31], using a panel sample of 83 incumbent pharmaceutical firms during the period 1986-2000, find that internal R\&D and external R\&D, through either R\&D alliances or R\&D acquisitions are complementary innovation activities at higher levels of in-house R\&D investments, whereas at lower levels of in-house R\&D efforts, internal and external R\&D turn out to be substitutive strategic options. Kang et al. [38] show that external technology acquisition has an inverted U-shaped relationship with subsequent technology innovation performance, and that is not complementary to internal R\&D activities.

Bena and Li [7], using a large sample of acquirers with patents and targets with patents over the period 1984 to 2006, focus on corporate innovation activity as a source of synergy. They find that firms with large patent portfolios and low R\&D expenses are more likely to be acquirers, while R\&D-intensive firms with slow growth in patent output are more likely to be acquired. Also, technological overlap between firms' innovation activities has a positive and significant effect on the likelihood of a merger pair formation. The likelihood of a merger is reduced for firm pairs that also overlap in product markets. Finally, they show a positive treatment effect of a merger on post-merger innovation output when there is premerger technological overlap between merging firms. They conclude that synergies obtained from combining 
innovation capabilities are an important motivation for corporate acquisitions. The findings of their paper suggest several new directions for future research and they mention first that their paper highlights that many merger transactions are driven by efficiency motives.

Our paper tries to contribute to previous literature relating lab efficiency as a whole to internal and external $R \& D$ strategies. The novelty of our approach is that we consider large laboratories from different countries and, simultaneously, we combine in a novel way alternative sources of data -Datastream, the European Medicines Agency (EMA) and the US Food and Drug Administration (FDA)- to select and construct relevant inputs and outputs that characterize the production and innovation activity of large pharmaceutical companies. Previous papers have estimated either DEA efficiency or DEA total factor productivity of pharmaceutical laboratories, but most of them consider laboratories from a single country [27, 33, 43] or consider innovation in several countries but the unit analyzed is not the pharmaceutical laboratory but the country itself $[29,50]$.

In addition, when measuring R\&D efficiency of either countries or pharmaceutical firms, most previous papers consider the number of patents as a proxy for $R \& D$ output $[19,30,37]$. In our study, as a proxy for $R \& D$ output we consider not only the number of new chemical entities (excluding generics) approved by the EMA and the FDA for each laboratory, but also we adjust this figure considering the specific date of authorization of each approved medicine. Although studies considering patents adjust for the quality of patents by considering the number of times that a patent has been cited, in our case only the most successful new drugs in the pharmaceutical pipeline (after a successful Phase III evaluation) are approved by the EMA and/or the FDA, so we consider this measure to be a better proxy for successful R\&D than patents.

We consider a common efficiency frontier for large pharmaceutical firms irrespective of their country of origin given that they compete with each other when trying to obtain new drug authorizations from the EMA and/or the FDA. Also, firms with authorized medicines sell the same chemical entities in many different countries, and global investors in the pharmaceutical sector analyze the big laboratories' returns and risks when deciding on portfolio weight and diversification issues. So pharmaceutical companies are global in several dimensions.

After dropping laboratories with any missing values, we end up with a final sample of 37 large firms. If these are compared with the Datastream sample of 241 companies, our sample accounts for more than $80 \%$ of market value, net sales and net income. Thus, we believe that our 37-laboratory sample is significantly representative of the pharmaceutical industry.

This article aims to measure first the relative efficiency of a sample of 37 large pharmaceutical laboratories from different countries, which can be considered representative of this industry, in the period 2008-2013 using a Data Envelopment Analysis (DEA) non-parametric approach. Our results suggest that the pharmaceutical industry is a competitive sector with many laboratories at the efficient frontier and many inefficient laboratories close to the frontier. Then, we split our sample into efficient labs and inefficient labs and we analyze in detail financial transactions announced by efficient and inefficient labs. 
The paper proceeds as follows. Section 2 describes efficiency measurement in pharma labs, section 3 discusses DEA efficiency results, and section 4 analyzes M\&A as well as other announced transactions by efficient and inefficient pharmaceutical laboratories. Conclusions are drawn and suggestions for future research are given in section 5 .

\section{Efficiency measurement in pharmaceutical firms.}

The development of a globalized economy has led to a new environment, in which international competitiveness has become fierce and where the concept of 'efficiency' has become strategically important. The pharmaceutical sector, in which R\&D is key, is no exception and competition in it has increased dramatically. So, given the importance of this industry from both the political-economic and the ethical-healthcare points of view, this paper aims, as a first stept, to measure the efficiency of large pharmaceutical firms.

The pharmaceutical industry is very important not only in health terms but also in economic terms, so it is relevant to study its internal and external $R \& D$ activity at both industry and laboratory level, and from the perspectives of public [9] and private funding of R\&D. In addition, pharmaceutical companies have engaged in R\&D collaboration not only with other laboratories but also with other firms and universities [45]. According to the IMS Institute [35], spending on medicines will reach nearly 1.3 trillion USD in 2018. This would mean an average annual growth of $6 \%$ over the period 2009-2018. The pharmaceutical industry is therefore a key sector. Few other industries can match its contribution to investment in $R \& D$, trade balance, and creation of skilled employment.

Nonetheless, this sector faces major challenges in the current context. In addition to regulatory hurdles and escalating R\&D costs, it has been severely hit by the impact of fiscal austerity measures. How pharmaceutical companies -and related stakeholders- approach these problems may impact both the worldwide economy and the future health of the world population.

In this concentrated industry, the ten largest pharmaceutical laboratories represent approximately one third of the global market. Six of them are from the US, while the remaining four are from Europe. A study by the IMS Institute [34] highlights that, although there has been rapid growth in emerging economies (such as Brazil, China, and India), North America and Europe currently account for more than 50\% of global spending, which justifies the use of the EMA and the FDA in this study.

Regarding the analysis of efficiency in the pharmaceutical sector, most of the literature has centered on Asian countries. One of the earliest studies was by Honjo and Haneda [33], who analyzed the efficiency of fourteen Japanese pharmaceutical firms over the period 1977-1991 with a DEA model comprising one input and two outputs.

You et al. [59] measured the efficiency of pharmaceutical firms and identified their determinants using Korean and American samples. They used four different types of efficiency (cost, allocative, technical and 
scale) based on DEA and, by means of regression techniques, studied the impact of ownership structure, $R \& D$ investment, and scale economies. Mao et al. [43] evaluated the business performance of thirty-four Chinese pharmaceutical companies using DEA. They considered three inputs (size of the workforce, administrative expenses, and gross assets), and one output (operating revenue). This study concluded that the overall efficiency of this sector in China was not high. Other studies have used this methodology to rate pharmaceutical firms in India [44] and Iran [36].

In this sector, innovation is of special importance from a health perspective, so the importance of $R \& D$ should be considered in the analysis. Wang and Huang [56] evaluated the relative efficiency of R\&D activities across countries. These authors used patents and academic publications as outputs. Hashimoto and Haneda [30] focused on the R\&D efficiency of pharmaceutical companies in Japan and considered that the efficiency frontier shifted over time. As an input, they used R\&D expenditure and considered three outputs: patents (as a proxy of invention), pharmaceutical sales (as a proxy of product innovation), and operating profit (as a proxy of process innovation). Shimura et al. [52] used one input (R\&D expenditure) and three outputs (sales, operating profit, and the accumulated number of weighted new molecular entities approved by the Japanese Ministry of Health) to measure R\&D productivity. Cruz-Cáceres et al. [19] discussed the relationship between innovation and performance and proposed a new approach to tackle it, using R\&D capital stock and highly-skilled staff as innovation inputs, and new products and patents as innovation outputs.

\subsection{DEA optimization technique.}

A company's business efficiency can be defined as the relation between the value created and the resources used for creating it [6]. It is a broad term that can be assessed by considering a single ratio or by means of several inputs to consider resources employed and outputs to express value creation.

When measuring the efficiency of a company, the literature offers a wide variety of alternatives for inputs and outputs depending on the authors' approach. A general pattern does exist, however. Input variables tend to represent investment metrics, both tangible -such as number of employees, number of branches, and administrative expenses [58]- and intangible -like product and process knowledge [2]. On the other hand, output variables are generally key performance indicators, both in absolute -such as profit, market share, and market value [55]- and in relative terms -like profit ratio, return on assets, and B/M ratio [57].

Under these circumstances, DEA is a common approach for studying business efficiency. Cooper et al. [18] define DEA as a "data oriented approach for evaluating the performance of a set of peer entities that convert multiple inputs into multiple outputs" (see section 3.1 for a detailed description). For this reason, this technique has been used to measure relative efficiency in different kinds of entities, such as hospitals [11, 41], universities [51], retail stores [55], banks [58], airports [48], holdings [57], and sport teams [24].

Figure 2 outlines the approach followed for assessing the efficiency of pharmaceutical companies. It is mainly based on a four-step process. The first one is the study of strategic issues -the pharmaceutical sector (and its distinctive features) and DEA-based techniques. The second one aims to determine how efficiency 
must be measured in this environment. Note that DEA allows the efficiency of companies to be measured from a multidimensional perspective, so several inputs and outputs are defined. The third one is the construction of the DEA model under two different assumptions: constant returns-to-scale (CRS) and variable returns-to-scale (VRS). In the last step, results are analyzed from a double perspective. On the one hand, the efficiency of a relevant sample of the world's leading pharmaceutical companies is evaluated, which is the main goal of the paper. On the other hand, the peers, i.e. references at the frontier for inefficient firms, are discussed.

Additionally, and as intermediate steps in the evaluation process, data, results, and consistency must be checked. Data are checked to verify that the DEA model can operate with the defined combination of inputs and outputs (e.g. with non-negative values, or with constraints in the available data), while results are checked to study the representativeness of the solutions. Finally, consistency is checked to ensure that the results are sufficient to draw conclusions, so a number of models are created. For reasons of space, in this paper we only discuss the three final models. The whole process was carried out during five months, with weekly meetings of an interdisciplinary group of five people, some of them experts in the methodology and others with proven knowledge of this sector.

\section{PLEASE INSERT FIGURE 2 ABOUT HERE}

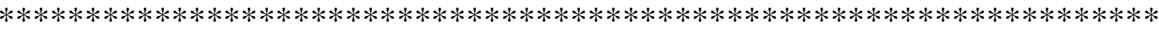

In the original study by Charnes et al. [13], DEA is described as a "mathematical programming model applied to observational data that provides a new way of obtaining empirical estimates of relations -such as the production functions and/or efficient production possibility surfaces- that are cornerstones of modern economics".

DEA is a non-parametric frontier-efficiency method using a linear programming technique for measuring performance. It assesses the relative efficiency of a set of decision making units (DMUs), pharmaceutical laboratories in this study, that are engaged in performing a similar function using a set of inputs (related to investment by the firms) to produce a set of outputs (indicators of their performance). When a DMU maximizes the relationship between outputs and inputs, it is located on the frontier, and is regarded as an efficient unit $(100 \%)$. If not, the relative efficiency of the DMU is measured in the interval $(0 \%, 100 \%)$ subject to the absolute efficiency of the DMUs on the frontier, which reveals that this efficiency could be improved by changing the proportion among inputs. Subsequently, the DMUs can summarize the quantitative index of overall efficiency and hence can be ranked by scale.

DEA has been widely used by researchers in a number of fields for modeling operational processes for performance evaluations, in governmental and nonprofit sectors and in regulated and private sectors. These multiple applications were supported by further development by Zhu [60], who tested a number of DEA models that can be used in performance evaluation and frontier estimation. 
DEA can be carried out under the assumption of CRS or VRS -i.e. by introducing a scale constraint in the model, hence DMUs are not penalized for operating at a non-optimal scale [4].

Under the VRS approach, the CCR model (from the CRS approach) [13] becomes the BCC model if the convexity constraint is added. This classic DEA-based model in its output-oriented form to measure efficiency is formulated by (1), where $n$ is the number of DMUs (general index $i$, while $l$ is the index of the specific DMU whose efficiency is being assessed), $m$ is the number of inputs (general index $j$ ), $p$ is the number of outputs (general index $k$ ), $\lambda_{i}$ are the multipliers used for computing linear combinations of the DMU's inputs and outputs (i.e. the model's decision variables), $x_{i j}$ is the observed amount of input $j$ of DMU $i$, and $y_{i k}$ is the observed amount of output $k$ of DMU $i$. Note that $\varphi^{*}$ refers to the optimal efficiency score of a DMU. That is, if $\varphi^{*}=1$, DMU $l$ is technically efficient. Note that both the CCR and the BCC models are radial projection constructs for characterizing efficiency, unlike other models such as non-radial ADD [14]. Finally, both models are invariant to the units of measurement.

Maximize:

$$
\varphi^{*}=\max \varphi
$$

Subject to:

$$
\begin{gathered}
\sum_{i=1}^{n} \lambda_{i} x_{i j} \leq x_{l j} ; \text { for } j=1,2, \ldots, m \\
\sum_{i=1}^{n} \lambda_{i} y_{i k} \geq \varphi y_{l k} ; \text { for } k=1,2, \ldots, p \\
\sum_{i=1}^{n} \lambda_{i}=1 ; \text { for } i=1,2, \ldots, n \\
\lambda_{i} \geq 0 ; \text { for } i=1,2, \ldots, n
\end{gathered}
$$

The work by Barr [5] can be consulted to decide between the technological choices that are currently available to implement DEA. In order to estimate relative efficiencies under the standard CRS and VRS models we used the DEAP software developed by Professor Tim Coelli. In particular, to solve the linear programming problems this study used DEAP 2.1 software [15], which is also valid for computing Malmquist DEA, i.e. for calculating indices of total factor productivity (TFP).

Some studies estimate Malmquist productivity indexes (TFP indexes) using DEA and break them down into sources of productivity change. We did not calculate TFP given that a data set with no missing values is needed in all the relevant years (from 2008 to 2013 in our case). The Malmquist productivity index was introduced by Caves et al. [12] as the ratio of two distance functions pertaining to distinct time periods. There are several alternative ways to compute TFP. For a discussion and for an empirical example applied to pharmaceutical laboratories in Spain, see [27]. For a study on the dynamics of technological innovation, see [1].

\subsection{Data selection and DMUs.}


This research uses data within the 2008-2013 time period obtained from three main sources: the FDA, the EMA, and Datastream. The FDA and the EMA are responsible for protecting and promoting public health in the US (the former) and the EU (the latter) through the regulation and supervision of medicines. They require that each new medicine is evaluated through various phases of clinical trials. Both agencies maintain a historical database with all medicines approved ${ }^{1}$. Data was also taken from Datastream, a global financial and macroeconomic database.

Initially, we focused on a list of 241 large pharmaceutical laboratories taken from Datastream (TR GLOBAL PHARMA list) and generated on $4^{\text {th }}$ June 2014. All financial information from large laboratories from different countries was generated in USD.

We then identified the Datastream constituents with financial information in the study period 2008-2013 and computed an average for each of the financial variables considered over the study period. We chose an average in order to deal with possible missing values in any given year for specific laboratories. We also considered the sum of all values for each variable (instead of the average) with no significant changes in efficiency estimates.

Subsequently, we searched for Datastream laboratories with new chemical entities approved by the EMA and FDA during the study period (at least one drug authorized in the period 2008 to 2013 by EMA or FDA). Our final sample is made up of 37 pharmaceutical laboratories, which are the DMUs in our research, with full Datastream information and also with new drugs approved by the EMA and/or FDA in the period 20082013.

Given that there were 241 pharmaceutical laboratories in the original Datastream list and that a balanced data set with no missing values in any of the variables is needed in order to estimate DEA relative efficiencies, two important issues must be taken into account in order to try to assure that our final sample of 37 laboratories represents the large pharmaceutical sector.

The first is to know if the economic activity of our sample of 37 large laboratories represents a large proportion of the total activity of the pharmaceutical laboratory sector. The second is related to the absence of a time dimension in our DEA model because a time dimension is only included in our DEA analysis when discounting the number of days that a new drug has been authorized.

To address both issues, we compared the market capitalization, net sales, and net income of the Datastream list of 241 laboratories versus those of the final 37 laboratories year by year. Our 37 laboratories were seen to represent $80 \%$ of the market value of the 241 laboratories, and similar figures were obtained for net sales and net income. Thus, this analysis suggests that our 37 laboratories represent a large proportion of the large pharmaceutical companies' economic activity. However, the time effect over the period 2008 to 2013

\footnotetext{
${ }^{1}$ Large pharmaceutical companies operate globally, so they market their innovative drugs in more markets than Europe and the USA. Thus, our measure for innovative drugs that have been authorized by the EMA and the FDA for a given laboratory is a proxy for the expected authorization of the same innovative drug for other markets. Europe and USA are two key markets, and an innovative drug can be expected to be innovative in all the relevant markets. Given that laboratories operate globally, we consider our proxy to be a good one.
} 
shows that laboratories excluded from the 37 gained increasing importance in terms of creating value, increasing sales and increasing net profit. The details are shown in Table A.1 of Appendix A.

Given that the number of new drugs authorized by the EMA [22] or the FDA [23] per year is very small, we accounted for the aggregate number of drugs authorized to each laboratory over the whole period 2008 to 2013. It must be stressed that we only consider innovative drugs, i.e. generic drugs are NOT taken into consideration and are totally excluded from our analysis. If we had considered new drugs authorized per year, we would have had to rule out additional laboratories every time they had no authorized new drugs in a given year and we would not have been able to compute the DEA efficiencies at the year level for such laboratories.

\subsection{Description of variables: Inputs and outputs.}

In this non-parametric DEA approach aimed at measuring the relative efficiency of pharmaceutical laboratories, we used different combinations of inputs and outputs in order to measure the performance of the laboratories and applied sensitivity techniques to verify the consistency of the results. This selection of the inputs and outputs of the model is a key part of a DEA study. The larger the number of inputs and outputs, the less discriminatory the model becomes. Boussofiane et al. [8] stated that, as a rule of thumb, in most situations satisfactory discrimination is obtained if the number of units in the assessment set (DMUs) is three times the number of inputs times the number of outputs. Cooper et al. [17] uphold that the number of DMUs should be at least three times higher than the number of inputs and outputs. The more inputs and ouputs included in a DEA model, the higher the relative efficiency and the higher the number of laboratories that are likely to be at the efficient frontier. There should be a balance between including all relevant inputs and outputs and being able to differentiate between efficient and inefficient labs.

Seven variables were used in the final models to measure the business efficiency of large pharmaceutical firms in the period 2008-2013. Three of them were considered inputs, and another three outputs. The remaining one was considered both an input and an output in different models as it may be understood either way.

The inputs (I1, I2, I3) represent proxies of the investment in innovation by the pharmaceutical firms:

- Size of the workforce $(I 1-S W)$. This refers to the average number of employees in the company (including all the business functions) in the above-mentioned period.

- Total assets (I2-TA). This is expressed as the average assets (land cost, building cost, inventory, machine and equipment, and so forth) of the company in the above-mentioned period, which represent a measure of the total size of the company.

- Investment in $R \& D(I 3-I R D)$. This is the average expenditure by the company on R\&D from 2008 to 2013.

The outputs $(\mathrm{O} 1, \mathrm{O} 2, \mathrm{O} 3)$ are common indicators, related to the firms' main goals: 
- Net profit (O1-NP). This variable considers the average net results (i.e. after depreciation, amortization, interest, and tax) in the period 2008-2013.

- Market capitalization (O2-MC). This refers to the average market value of the company from 2008 to 2013. Unlike the previous variable, this one takes into account not only the company's current results, but also its expectations for the future ${ }^{2}$.

- Total sales (O3-TS). This is expressed as the average sales of the company within the above-mentioned time period and contains information on one of the key indicators in companies, market share.

Many of our 37 laboratories have zero drugs authorized in a given year and DEA requires a balanced data set in order to compute the frontier and estimate relative efficiencies. Given that we take averages for financial data, we also had to add up all the new drugs during the period. One simple alternative would have been to directly consider the number of new chemical entities authorized by EMA and/or FDA during the study period from 2008 to 2013. However, it is not the same to have a new drug authorized at the beginning of the study period (generating cash flow during the whole period) than at the end of the study period. We show in Table A.2 of Appendix A the evolution over time of new drugs authorized by EMA and/or FDA. We also show the accumulated number of days until $31^{\text {st }}$ December 2013 and the number of days discounted. To account for this time effect, we computed a new variable that we define below.

In any case, it is striking from our authorized drug sample summarized in Table A.2 that the number of new drugs authorized by the EMA, in any of the years between 2008 and 2013, is higher than the number of new drugs authorized by the FDA. We carefully double-checked our database and, to the best of our knowledge, we believe that the authorized drug information has been extracted correctly. Thus, our interpretation of the available data is related to the fact that there is not a clear-cut difference between a really new chemical entity and a generic drug. There is a grey zone in between for drugs that are not a radical innovation but an incremental innovation. This may explain why in Table A.2 of the appendix, the EMA has more authorized new drugs than the FDA. The EMA database includes generic and non-generic drugs and provides a field named "generic", while the FDA separates new chemical entities from the rest.

As mentioned above, one variable is considered both an input and an output:

- Number of days of authorized innovative medicines considering the time effect (I4/O4-NDAIMCTE). A simple approach for considering new authorized drugs in the analysis would have been just to count the number of authorized drugs per laboratory during our study period. However, we wished to take into account the time effect. Thus, NDAIMCTE refers to the number of days that each innovative medicine has been authorized in the US and in the EU until the end of the period (or until the date of removal, if the

\footnotetext{
${ }^{2}$ Market capitalization is the result of a consensus in the market about current cash flows and expected future cash flows. In the case of pharmaceutical labs, it takes into account innovative drugs that are in the pipeline but have not yet been authorized because they are in the different phases of clinical research (Phase I, Phase II, Phase III), as well as some innovative drugs that have been authorized but are still in postmarketing surveillance (Phase IV).
} 
medicine is no longer sold), taking into account the time effect -in order to consider the decline in innovation in medicines as time passes.

Note that, although both the EMA and the FDA also provide information for new generic drugs, which are a very important part of the pharmaceutical drugs picture [25], there were substantial differences between EMA generic authorizations and FDA generic authorizations. This is because the FDA considered many minor changes as new authorizations so these were not directly comparable to EMA generic authorizations.

This final variable was devised from the initial variable 'number of authorized innovative medicines', with the aim of checking consistency in the results. After exploring several alternatives, the time effect -required for modeling the passing of time on the effect of an innovative medicine on company profits- was introduced by means of a mathematical function expressed in (2). Equation (3) represents the value of this variable for each medicine. Afterwards, the local results were added to obtain the global value of each laboratory. Note that $t_{F}$ refers to the end of the period (31 $1^{\text {th }}$ December 2013) or date of removal and $t_{0}$ represents the date of authorization. After testing several alternatives, the parameters were set at the values $k_{1}=0.000632208$ and $k_{2}=0.01$.

$$
f(t)=1-k_{2}\left(e^{k_{1}\left(t-t_{0}\right)}-1\right)
$$

NDAIMCTE

$$
\begin{aligned}
& =\int_{t_{0}}^{t_{f}}\left[1-k_{2}\left(e^{k_{1}\left(t-t_{0}\right)}-1\right)\right] d t=\int_{0}^{t_{f}-t_{0}}\left[1-k_{2}\left(e^{k_{1} \Delta t}-1\right)\right] d \Delta t= \\
& =\left[\left(1+k_{2}\right) \Delta t-\frac{k_{2}}{k_{1}} e^{k_{1} \Delta t}\right]_{0}^{t_{f}-t_{0}}=\left(1+k_{2}\right)\left(t_{f}-t_{0}\right)-\frac{k_{2}}{k_{1}} e^{k_{1}\left(t_{f}-t_{0}\right)}+\frac{k_{2}}{k_{1}}
\end{aligned}
$$

Table 1 presents the descriptive statistics of the seven variables considered for the database comprising 37 pharmaceutical laboratories.

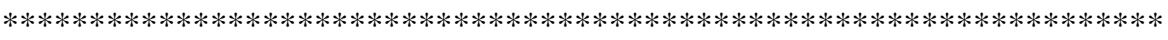

PLEASE INSERT TABLE 1 ABOUT HERE

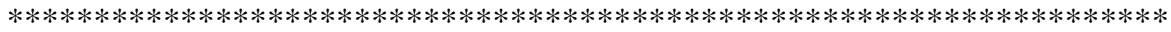

The dataset for the 37 pharmaceutical laboratories and the seven relevant variables (inputs and outputs) for the different DEA models are given in Tables B.1 and B.2 of Appendix B.

\subsection{Models.}

The iterative process followed led to the consideration of three models that are summarized in figure 2.

\section{PLEASE INSERT FIGURE 3 ABOUT HERE}


Model I only considers the six macroeconomic variables (three inputs and three outputs) explained above. Models II and III take into account the NDAIMCTE variable: model II as an input, and model III as an output. A double approach is adopted for this variable according to the following interesting interpretations:

- NDAIMCTE can be understood as an input, because the more approvals of medicines the laboratory has, the more its outputs can be expected to improve (more sales, more net income, and more market value). That is to say, this approach considers that the authorization of a medicine makes sense only if reflected in these indicators.

- NDAIMCTE can be considered an output, because the higher the inputs (the more employees the laboratory has, the bigger the investment, and the more investment in R\&D), the more authorizations of medicines it can expect. In other words, if this variable is set as an output, the model measures how efficient the laboratory is in developing new products. This approach, which considers innovative medicines as an output indicator, highlights the importance of innovation in this sector.

For the three models, we consider an output-oriented DEA model where there are as many objectives as output variables in each case- net profit, market capitalization and total sales -and the issue of new drugs in model II.

It is also important to consider the relationship between the number of DMUs and the number of inputs and outputs in the model. Since the number of DMUs (37) is more than three times higher than the numbers of inputs and outputs (6 in model I, and 7 in models II and III), the Cooper et al. [17] criterion is verified, hence the models are appropriate. Regarding the Boussofiane et al. [8] criterion, satisfactory discrimination is obtained as the number of inputs is at least three times the number of inputs times the number of outputs (9 in model I, 12 in models II and III).

Note that our iterative process led us to study different alternatives. Our first approaches were based on considering the NDAIMCTE as a core output in the study. However, when considering new authorized drugs, not all of them are equally innovative or equally successful. Innovation is difficult to measure, while success is difficult to predict. Researchers approach this problem in different ways. Kesselheim et al. [39] perform a systematic search for papers measuring drug innovation characteristics and compare different approaches. Light [42] evaluates drug innovation from 1982 to 2003 in three geographic areas (the US, Europe, and Japan) by calculating the "research productivity", which is defined as the ratio of the number of new molecular entities (NMEs) to the amount of investment in R\&D.

One way to capture this future uncertainty about the success of a new drug is based on including market capitalization as an output. Analysts following large pharmaceutical firms will recommend buying or selling shares according to the pipeline and future prospects of existing and yet to be drugs. On the other hand, current success of chemical entities is captured by total sales and net income. In summary, these three outputs (market capitalization, total sales, and net profit) are good proxies to capture the innovation and success of authorized new drugs. 
The use of these variables is a common approach. In their variable returns to scale DEA model, Shimura et al. [52] utilize three variables to evaluate R\&D productivity (cumulative R\&D expenses in the period 2002 to 2007, number of new molecular entities and aggregate net present value). In our analysis we had to decide whether to include only new chemical entities or to include both new drugs and generic drugs. After analyzing both databases (EMA and FDA), we decided to exclude generic drugs because, at the FDA, minor changes (i.e. in the prospect or leaflet) were included for generic drugs while this was not the case at the EMA.

\section{DEA efficiency: Results and discussion.}

The main efficiency results of this research are reported in this section. It should be clarified that, as previously explained, we evaluated the efficiency of the 37 pharmaceutical firms only under the VRS assumption because the CRS model is not valid given the importance of scale effects in the pharmaceutical industry ${ }^{3}$.

Table 2 reports the main results of models I, II, and III under the VRS assumption, in which the overall ranking is not influenced by the size of the company. The relative efficiencies of the 37 pharmaceutical laboratories are displayed. Note that, firstly, this table points out the companies that are relatively efficient in model I, and, secondly, their significant change rates (greater than 5\% in model II) are highlighted in bold in models III and IV. Table 3 summarizes the main results.

\section{PLEASE INSERT TABLE 2 ABOUT HERE}

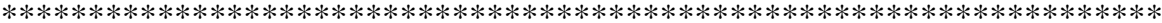

Table 3 shows that average efficiency rises to $93.45 \%$ in model II, while the number of efficient companies amounts to 21. These are ABBOTT, AMGEN, ASTELLAS, BAYER, CELGENE, CELLTRION, CSL, EISAI, GILEAS GLAXOSMITHKLINE, HOSPIRA, JOHNSON \& JOHNSON, MEDA AB, MEDICINES COMP., MERCK (KGAA), NOVO NORDISK, ORION, PFIZER, REGENERON, ROCHE and TEVA.

***************************************************************************

PLEASE INSERT TABLE 3 ABOUT HERE

${ }^{3}$ We thank one reviewer for this insight and suggestion. 
From table 2, it is possible to see that -as expected- more companies are judged to be part of the efficient frontier in models II and III since the number of variables is greater, so efficiency is measured over more dimensions.

When the NDAIMCTE variable is added to the model, average efficiency tends to increase, because the model is less discriminatory. Nonetheless, the increase is slight: $1.83 \%$ when it is considered an output, and $1.59 \%$ when it is considered an input. The number of efficient firms increases to 25 in the first case, as ELI LILLLY, NOVARTIS, SHIRE, and TAKEDA become efficient. In the second case, the number of efficient laboratories increases to 22 as BIOGEN becomes a new member of the frontier.

It must be highlighted that, given the slight change when the NDAIMCTE variable is considered either as an output (only five firms increase their efficiency more than 5\%) or as an input (four firms in this case improve their efficiency more than 5\%), the robustness of model I under the VRS assumption is verified. Thus, our study can be interpreted as a realistic approach for measuring efficiency in the pharmaceutical industry.

Broadly speaking, the results provide evidence of the good position of pharmaceutical companies in terms of competitiveness in innovation. In model I, 31 out of the 37 companies analyzed in this study present a level of efficiency greater than $85 \%$. In models II and III, this number increases to 32 .

Finally, table 4 presents the DEA-based analysis of peers for models II, III, and IV under the VRS assumption. The benchmark peers of each pharmaceutical company refer to the efficient laboratories that are taken as references to calculate their efficiency. Note that benchmark peers are ordered from the most influential to the least influential. Obviously, the most efficient companies do not have benchmark peers.

PLEASE INSERT TABLE 4 ABOUT HERE

\section{M\&A activity and other financial transactions by pharmaceutical laboratories}

In the introduction, we have indicated that large pharmaceutical laboratories have two nonexclusive alternatives for managing their portfolio of new drugs and we have discussed previous contributions. Simultaneously, they may develop new drugs internally but they may also engage in mergers and acquisitions or other transactions to obtain new drugs or to change the composition of their portfolio of promising drugs (selling new drugs and buying other types of new drugs).

In this section, we discuss, first, the direct effect of M\&A activity among laboratories with drugs authorized by EMA and FDA during our study period and, second, the effect of large and smaller transactions. We analyze the effect of large merger and acquisition (M\&A) activity (with direct effects on the number of new drugs authorized by EMA and FDA) in the pharmaceutical industry during the period 2008 to 2013 and its 
potential effect on the estimated DEA relative efficiency of pharmaceutical laboratories. Some pharmaceutical laboratories acquire other innovative laboratories that have new chemical entity authorizations from the EMA and the FDA. If we restrict the mergers considered in [16] to those that occurred during our study period, there were four major mergers (Pfizer+Wyeth 2009, Novartis+Alcon 2009, Roche+Genentech 2009 and Sanofi+Genzyme 2011) with acquirers from our sample of 37 laboratories and targets with new drugs authorized by either FDA or EMA. After considering the four large successful M\&As relevant for our research, eleven additional new chemical entities were included in the list of drugs authorized by EMA and FDA.

We then re-estimated our DEA models, and found very small changes (or none at all) in the relative efficiencies of pharmaceutical laboratories. Table A.3 in the appendix describes new drugs authorized by EMA and FDA to laboratories that do not belong to our sample of 37 laboratories but to laboratories that have been acquired by, or have merged with, any of our 37 laboratories.

In order to further address financial transactions by pharmaceutical labs, we also obtained much more detailed data on transactions announced by our 37 pharmaceutical laboratory sample in the period 20082013. We provide two summary tables (transactions announced by year and by pharmaceutical lab) including information about all announced transactions from the S\&P Capital IQ transactions database performed by our sample of 37 pharmaceutical laboratories during the period 2008-2013. In total, 2071 transactions were announced by our sample of large pharmaceutical labs. Transactions include merger and acquisitions, private placements and Buybacks.

PLEASE INSERT TABLE 5 ABOUT HERE

*****************************************************************************

The total size of announced transactions during the study period for our sample of laboratories was 982,036 million USD. Given that for some of the 2071 transactions the size was not reported, this is a conservative figure.

***************************************************************************

PLEASE INSERT TABLE 6 ABOUT HERE

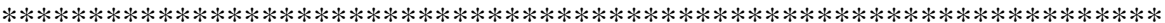

We split our sample in two. One subsample is made up of 21 efficient laboratories that are at the DEA frontier according to our DEA model I and the other is made up of the remaining 16 inefficient labs. Our sample of inefficient laboratories has an average efficiency of $84.8 \%$.

The size of the announced transaction was not available for all transactions (in smaller transactions some transaction details were not reported). Whenever this information was available, we used it to estimate the total size of these announced transactions for the two subsamples (efficient laboratories and inefficient labs). 
We now make a simple comparison of these two subsamples. The total number of announced transactions is very similar in our two subsamples: 1,025 announced transactions by 21 efficient laboratories, and 1,046 announced transactions by 16 inefficient laboratories. On average, each efficient laboratory made 48.8 transaction announcements during our study period while each inefficient laboratory made 65.4 .

The average size of the announced transactions is higher for efficient laboratories $(575,039 \mathrm{~mm}$ USD) than for inefficient laboratories (407,258 mm USD).

As a robustness check, we excluded Mitsubishi (an inefficient laboratory with 365 announced transactions) from the comparison given that this company is a conglomerate and some announced transactions are not directly related to the pharmaceutical sector. Once Mitsubishi is excluded, the total number of announced transactions is: 1,025 transactions by all efficient laboratories (as before) and only 681 transactions by all inefficient laboratories in our sample. On average, each efficient laboratory made 48.8 transaction announcements during our study period (as before), while on average each inefficient laboratory (excluding Mitsubishi) made 45.4.

As an additional robustness test, we used yearly data on announced transactions during our study period to run two OLS regressions, see (5) and (6). The results are shown in table 7, see respectively OLS 1 and OLS 2.

$$
\begin{gathered}
\frac{\text { Announced Transaction SIZE }_{i t}}{\text { Total Assets }_{i}}=\beta_{0}+\beta_{1} \cdot \frac{R \& D_{i}}{\text { Total Assets }_{i}}+\beta_{2} \cdot \text { Efficiency }_{i} \\
\frac{\text { Announced Transaction SIZE }_{i t}}{\text { Total Assets }_{i}}=\beta_{0}+\beta_{1} \cdot \frac{R \& D_{i}}{\text { Total Assets }_{i}}+\beta_{2} \cdot \text { EfficiencyDummy }_{i}
\end{gathered}
$$

\section{PLEASE INSERT TABLE 7 ABOUT HERE}

***************************************************************************

The dependent variable is the size of the total transactions per year per lab divided by average total assets of the lab during the study period. There are two independent variables: the ratio of R\&D to total assets, and a measure of efficiency (either relative efficiency of each pharma lab during the whole study period or, alternatively, a dummy that takes value 1 when the pharma lab is at the frontier and zero otherwise).

In both cases, our two OLS regressions show that both R\&D/TA and Efficiency (or efficiency dummy) have a positive and significant impact on the number of announced transactions relative to total assets. That is to say, the labs that invest more in R\&D and that have with higher DEA efficiency strike more deals (more announced transactions relative to the size of the lab measured as total assets). Relative Efficiency is significant at the $1.5 \%$ level and the efficiency dummy is significant at the $1 \%$ level. $R \& D$ relative to total assets is also significant at the $1 \%$ level in both OLS regressions.

Given our study period and considering only 36 laboratories, in our two OLS regressions, efficient laboratories make on average more transaction announcements, and the relative size of each transaction 
announcement is higher. Also, labs with more R\&D relative to total assets strike more deals than labs with lower $\mathrm{R} \& \mathrm{D}$ relative to total assets.

We ran two additional OLS regressions with an interaction term in each regression, see (7) and (8) corresponding to OLS 3 and OLS 4 in table 7.

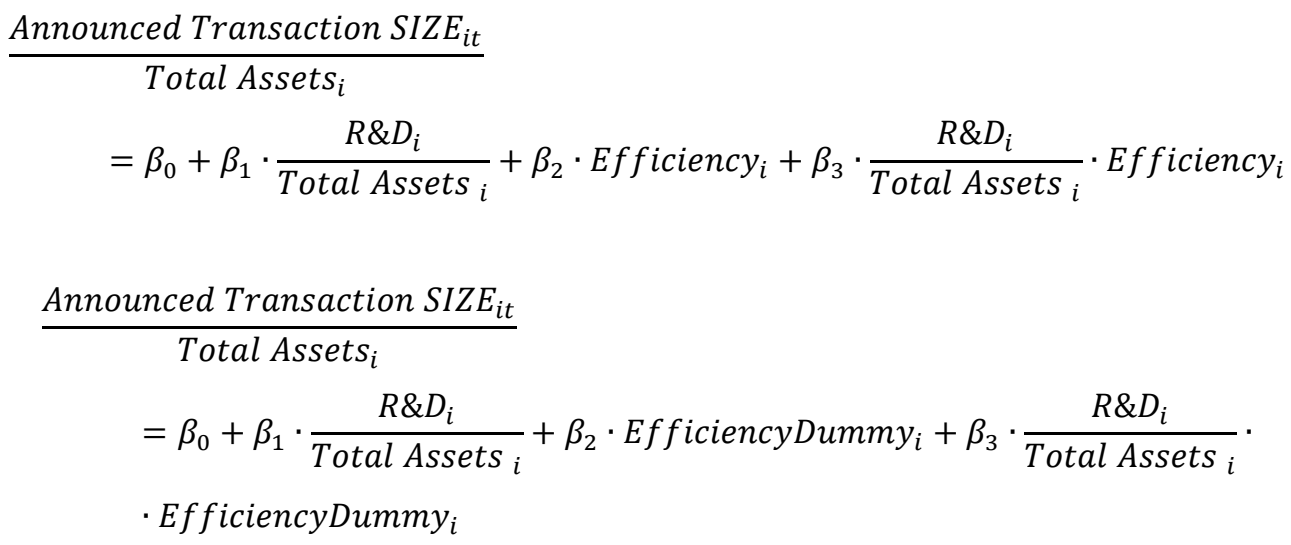

After including the interaction term, results continued to be significant and positive for the estimates of $\beta_{1}$ and $\beta_{2}$ and the estimate of the interaction term $\beta_{3}$ is significant but negative. We interpret the results as follows.

When we include the interaction term, the interpretation of this interaction term is that the labs that simultaneously are both more efficient and also invest more internally in R\&D relative to total assets, announce smaller transactions relative to total assets of the lab (if you are very efficient and you invest more in $R \& D$ then you do not need so much to make more external acquisitions and other transactions).

One concern when interpreting the results of our regression results would be that $\mathrm{R} \& \mathrm{D} / \mathrm{TA}$ is a ratio variable made up of two variables that are also inputs in our DEA efficiency models. Thus, it is important to check if the two regressors (R\&D/TA and Efficiency) are independent or not (if they are weakly or strongly correlated). If they were strongly correlated, our OLS results would be biased. We tried to assess whether R\&D/TA and DEA efficiency (or DEA efficiency dummy) are independent of each other or not. First, we analyzed the correlation matrix of all the variables used in our four regressions. Also, we made two additional regressions (R\&D/TA on DEA efficiency and R\&D/TA on DEA efficiency dummy). The R square is 0.0022 in one case and 0.0409 in the other. Given these robustness checks, we conclude that the results obtained in our OLS models are valid and not biased. For reasons of space, we do not report the correlation matrix and the extra regressions although they are available upon request.

\section{Conclusions.}

This paper estimates the relative efficiency in the period 2008-2013 of 37 large pharmaceutical firms that received authorization for innovative medicines in the United States and/or the European Union within this 
time period. Authorized drugs are concentrated in a small number of large and efficient pharmaceutical laboratories and it make sense for health authorities at the national level in the US (FDA) or at the European level (EMA) to discuss R\&D strategies for the future with a small number of large laboratories. In addition, we analyze announced financial transactions by our sample of pharmaceutical laboratories as an alternative way to gain access to new drugs and new R\&D.

The novelty of our approach is that we considered 37 large laboratories from different countries in the period 2008 to 2013 and, simultaneously, we combined information from several different sources: Datastream financial and market information, EMA, and FDA drug approvals and announced financial transactions from Capital IQ.

Although studies considering patents adjust for the quality of patents considering the number of times that a patent has been cited, in our case, only the most successful new drugs in the pharmaceutical pipeline are approved by EMA and FDA, so this measure is a better proxy for successful R\&D.

We used DEA non-parametric techniques, considering multiple inputs and outputs, and defined several dimensions in which large laboratories are considered to be efficient. While the inputs refer to different ways of measuring investment in the company, the outputs consider performance indicators. The relevance of $R \& D$ in this sector was also taken into special consideration. 21 companies proved to be efficient and 16 inefficient when considering three inputs and three outputs under the VRS assumption. The average level of efficiency in the base model was $93.45 \%$. In addition, 10 companies are not efficient, but present a level of efficiency greater than $85 \%$. Broadly speaking, this indicates the high competitive level of companies in this sector.

Some previous papers estimate either DEA efficiency or DEA total factor productivity of pharmaceutical firms but most studies focus on a single country. Also, when measuring R\&D efficiency, most previous papers consider the number of patents as a proxy for R\&D. In this study, as a proxy for R\&D we considered not only the number of new chemical entities approved by EMA and FDA for each laboratory but we also adjusted this figure considering the specific date of authorization of each new chemical entity.

Shimura et al. [52] perform statistical analysis to explore links between R\&D and industry consolidation in the period 2002 to 2007 considering a sample of 21 pharmaceutical laboratories. We, however, focus only on DEA estimates but consider more efficiency dimensions and we explore in detail peers at the frontier for the pharmaceutical laboratories that are not fully efficient. We perform an efficiency analysis without a DEA second stage approach given that DEA second stages are subject to some controversy as discussed above.

We extend prior literature related to markets for technology and internal and external R\&D strategy by considering in much more detail announced transactions and including not only a few very large M\&As or a few hundred acquisitions but also many smaller transactions.

Prior related contributions on acquisitions and innovation [3, 7, 16, 26, 31, 32, 38, 47, 52] focus on different characteristics of the acquirer and/or target and whether and how acquisitions create value. In our case, we 
estimate first the relative efficiency of each pharma lab and then we introduce financial transactions into the analysis. Thus, we searched for further evidence of the link between lab efficiency and financial transactions in the pharmaceutical industry during our study period. Large M\&As have been studied in previous papers but we contribute by analyzing in detail 2071 announced transactions by our sample of 37 laboratories. Our sample is split in two. One subsample is made up of 21 efficient laboratories that are at the DEA frontier according to model I. The second subsample is made up of 16 inefficient firms. After adjusting for the market cap of each pharmaceutical laboratory (as a proxy for size), the transaction size relative to the size of the pharmaceutical laboratory is slightly larger for efficient laboratories (0.597) than for inefficient laboratories $(0.530)$.

Given our study period and considering only 36 laboratories (excluding Mitsubishi), efficient laboratories make on average more transaction announcements, and the relative size of each transaction announced is higher. Also, labs with more $R \& D$ relative to total assets strike more deals than labs with lower $R \& D$ relative to total assets. However, when we include the interaction term, this term suggests that labs that simultaneously are more efficient and also invest more internally in $R \& D$ announce smaller transactions relative to total assets of the lab.

Although we think that new drugs authorized are a better proxy for successful research than patents, the authorization procedure is not perfect. New drugs submitted for authorization to EMA and FDA are subject to close scrutiny, especially during phase III. However, part of the results of the clinical trials is never published or is published with a considerable delay. Recent legislation tackles this problem. The USA passed legislation in 2007 and, in Europe, new legislation will come into force in 2016. The FDA has the power to fine laboratories that do not comply but it is reported that it has never actually done so [54].

We propose several possible extensions of our paper. We did not consider information from laboratories with zero new drugs authorized during the study period. This was because of our DEA methodology for estimating efficiency as well as the fact that many laboratories had zero new drugs authorized in many of the years of our sample. However, different approaches and a different methodology may be able to exploit the data in order to further contribute to the subject. Censored regression models could be used to incorporate more pharmaceutical laboratories into the analysis and to consider many laboratories with zero drugs authorized.

Alternatively, with an unbalanced data set, the use of panel data would be helpful in order to account for unobserved heterogeneity and to study the dynamics of the population. Pindado et al. [49] show how firm characteristics influence the relationship between $R \& D$ and firm value but, when constructing the unbalanced panel, they impose the restriction that there should be six consecutive years of information available from companies in the sample. This is only possible with a very large database comprising more sectors than the pharmaceutical sector. Another possible extension would be to estimate a two-stage DEA using, in the second stage, variables that were not used in the first stage. Explaining DEA inefficiency in a second stage analysis is a common practice for identifying factors whose impact on efficiency is statistically significant. However, the use of ordinary least squares, Tobit or other alternatives is subject to controversy, 
as well as to limitations and biases according to recent papers. Simar and Wilson [53] compare the pros and cons of the different alternatives, but one alternative which is not subject to controversy is to incorporate all the relevant variables in the first step. This is what we did.

In the case of EMA authorizations, there is authorization information since 1995 and, in the case of the FDA, there is information about new molecular entities since 1999 so this could be used to estimate changes in Total Factor Productivity adopting a DEA / Malmquist methodology in order to study the frontier shift, while also comparing relative efficiency and interpreting the individual evolution of companies. Another alternative would be to explore the differences between generics and new drugs authorized by EMA or FDA.

Another alternative for future research would be to identify the sources and key factors of innovation of the different laboratories in different geographical regions. These factors may be identified at firm level or at country or regional level. In the latter case, factors such as the regulatory environment or approval times are important for pharmaceutical innovations -see e.g. [10, 20, 21]. Recently, Kinch [40] used information on FDA approved NMEs and merged this information with patent information. Grabowski and Wang [28] is another relevant paper on the subject that finds that biotech and orphan products enjoyed tremendous growth, especially for cancer treatment. Naci et al. [46] examined why the drug development pipeline is not delivering better medicines. Finally, it would be possible to explore in much more detail announced financial transactions in order to gain further insights regarding external R\&D acquisitions.

\section{References.}

[1] Achilladelis, B., Antonakis, N.: The dynamics of technological innovation: the case of the pharmaceutical industry. Res. Policy 30, 535-588 (2001).

[2] Ahn, J.H., Chang, S.G.: Assessing the contribution of knowledge to business performance: the KP ${ }^{3}$ methodology. Decis. Support Syst. 36, 403-416 (2004).

[3] Arora, A., Fosfuri, A., Gambardella, A.: Markets for technology and their implications for corporate strategy. Ind. Corp. Change 10, 419-451 (2001).

[4] Banker, R.D., Thrall, R.M.: Estimation of returns to scale using Data Envelopment Analysis. Eur. J. Oper. Res. 62, 74-84 (1992).

[5] Barr, R.S.: DEA Software Tools and Technology: A State-of-the-Art Survey. Handbook on Data Envelopment Analysis. International Series in Operations Research \& Management Science 71, 539-566 (2004)

[6] Baršauskas, P., Šarapovas, T., Cvilikas, A.: The evaluation of e-commerce impact on business efficiency. Balt. J. Manag. 3, 71-91 (2008). 
[7] Bena, J., Li, K.: Corporate Innovations and Mergers and Acquisitions. J. Finance 69 1923-1960 (2014).

[8] Boussofiane, A., Dyson, R.G., Thanassoulis, E.: Applied Data Envelopment Analysis. Eur. J. Oper. Res. 52, 1-15 (1991).

[9] Bowns, S., Bradley, I., Kneec, P., Williams, F., Williams, G.: Measuring the Economic Benefits from R\&D: Improvements in the MMI Model of the United Kingdom National Measurement System. Res. Policy 32, 991-1002 (2003).

[10] Cabiedes, L.: Authorisation and Withdrawal of Pharmaceutical Innovations in the European. Working paper, University of Oviedo, Spain (2005).

[11] Castelli, A., Street, A., Verzulli, R., Ward, P.; Examining variations in hospital productivity in the English NHS. Eur. J. Health Econ. 16(3), 243-254 (2015).

[12] Caves, D., Christensen, L., Diewert, E.: The economic theory of index numbers and the measurement of input, output, and productivity. Econometrica 50(6), 1393-1414 (1982).

[13] Charnes, A., Cooper, W.W., Rhodes, E.: Measuring the efficiency of decision making units. Eur. J. Oper. Res.2, 429-444 (1978).

[14] Charnes, A., Cooper, W.W., Golany, B., Seiford, L.M., Stutz, J.: Foundations of data envelopment analysis and Pareto-Koopmans empirical production functions. J. Econometrics 30, 91-107 (1985).

[15] Coelli, T.J.: A Guide to Deap Version 2.1: A Data Envelopment Analysis (Computer) Program. Department of Econometrics, University of New England, Armidale, Australia (1996).

[16] Comanor, W.S., Scherer, F.M.: Mergers and innovation in the pharmaceutical industry. J. Health Econ. 32, 106-113 (2013).

[17] Cooper, W.W., Li, S., Seiford, L.M., Thrall, R.M., Zhu, J.: Sensitivity and stability analysis in DEA: Some recent developments. J. Prod. Anal. 15, 217-246 (2001).

[18] Cooper, W.W., Seiford, L.M., Zhu J.: Data Envelopment Analysis: History, Models, and Interpretations. Handbook on Data Envelopment Analysis. International Series in Operations Research \& Management Science 164, 1-39 (2011).

[19] Cruz-Cáceres, C., Bayona-Sáez, C., García-Marco, T.: You can’t manage right what you can’t measure well: Technological innovation efficiency. Res. Policy 42, 1239-1250 (2013).

[20] Danzon, P.M., Wang, Y.R., Wang, L.: The impact of price regulation on the launch delay of new drugs - evidence from twenty-five major markets in the 1990s. Health econ. 14(3), 269-292 (2005).

[21] Dukes, G.: The effects of drug regulations: A survey based on the European studies of drug regulation. MTP Press Limited, Lancaster, UK. (1985) 
[22] European Medicines Agency: European Public Assessment Reports. Available through http://www.ema.europa.eu/ema/index.jsp?curl=pages/medicines/landing/epar_search.jsp\&mid=WC0b01a c058001d125 (2015).

[23] Food and Drug Administration: Drug Approval Reports. Available through http://www.accessdata.fda.gov/scripts/cder/drugsatfda/index.cfm?fuseaction=Reports.ReportsMenu (2015)

[24] García-Sánchez, I.M.: Efficiency and effectiveness of Spanish football teams: a three-stage-DEA approach. Cent. Eur. J. Oper. Res.15, 21-45 (2007).

[25] Gascón, F., De la Fuente, D., Puente, J., Lozano, J.: On macroeconomic characteristics of pharmaceutical generics and the potential for manufacturing and consumption under fuzzy conditions. Artif. Intell. Med. 41, 223-235 (2007).

[26] Girotra, K., Terwiesch, C., Ulrich, K.T.: Valuing R\&D projects in a portfolio: Evidence from the pharmaceutical industry. Manage. Sci. 53(9), 1452-1466 (2007).

[27] González, E., Gascón, F.: Sources of productivity growth in the Spanish pharmaceutical industry (1994-2000). Res. Policy 33, 735-745 (2004).

[28] Grabowski, H.G., Wang, Y.R.: The quantity and quality of worldwide new drug introductions, 19822003. Health Affair. 25(2), 452-460 (2006).

[29] Guan, J., Chen, K.: Modeling the relative efficiency of national innovation systems. Res. Policy 41, 102-115 (2012).

[30] Hashimoto, A., Haneda, S.: Measuring the change in R\&D efficiency of the Japanese pharmaceutical industry. Res. Policy 37, 1829-1836 (2008).

[31] Hagedoorn, J., Wang, N.: Is there complementarity or substitutability between internal and external R\&D strategies? Res. Policy 41(6), 1072-1083 (2012).

[32] Higgins, M.J., Rodriguez, D.: The outsourcing of R\&D through acquisitions in the pharmaceutical industry. J. Financ. Eco. 80, 351-383 (2006).

[33] Honjo, Y., Haneda, S.: R\&D Evaluation of Japanese Pharmaceutical Firms Using DEA. Journal of Science Policy and Research Management 13, 96-105 (1998).

[34] IMS Institute for Healthcare Informatics: The Global Use of Medicines: Outlook Through 2015. Available through www.imshealth.com (2011).

[35] IMS Institute for Healthcare Informatics: Global Outlook for Medicines Through 2018. Available through www.imshealth.com (2014). 
[36] Jalili, M., Rangriz, H., Shabani, S.: Using Data Envelopment Analysis to Rate Pharmaceutical Comanies: A Case Study of Iran. Life Science Journal 10, 336-341 (2013).

[37] Jiménez-Sáez, F., Zabala-Iturriagagoitia, J.M., Zofio, J.L., Castro-Martínez, E.: Evaluating research efficiency within National R\&D Programmes. Res. Policy 40, 230-241 (2012).

[38] Kang, K.H., Jo, G.S., Kang, J.: External technology acquisition: a double-edged sword. Asian J. Techn. Innov. 23(1), 35-52 (2015).

[39] Kesselheim, A.S., Wang, B., Avorn, J.: Defining "innovativeness" in drug development: a systematic review. Clin. Pharmacol. Ther. 94(3), 336-348 (2013).

[40] Kinch, M.S., Raffo, J.: Sources of innovation: an assessment of intellectual property. Drug discov. today 20(5), 500-504 (2015).

[41] Kounetas, K., Papathanassopoulos, F.: How efficient are Greek hospitals? A case study using a double bootstrap DEA approach. Eur. J. Health Econ.14(6), 979-994 (2013).

[42] Light, D.W.: Global drug discovery: Europe is ahead. Health Affair. 28(5), w969-w977 (2009).

[43] Mao, Y., Li, J., Liu, Y.: Evaluating Business Performance of China's Pharmaceutical Companies Based on Data Envelopment Analysis. Studies on Ethno Medicine 8, 51-60 (2014).

[44] Mazumdar, M., Rajeev M.: A Comparative Analysis of Efficiency and Productivity of the Indian Pharmaceutical Firms: A Malmquist-Meta-Frontier Approach. Working Paper, The Institute for Social and Economic Change, Bangalore (2009).

[45] Motohashi, K.: The changing autarky pharmaceutical R\&D process: causes and consequences of growing R\&D collaboration in Japanese firms. Int. J. Technol. Manage. 39, 33-48 (2007).

[46] Naci, H., Carter, A.W., Mossialos, E.: Why the drug development pipeline is not delivering better medicines. BMJ, h5542 (2015).

[47] Nishimura, J., Okada, Y.: R\&D portfolios and pharmaceutical licensing. Res. Policy 43(7), 12501263 (2014).

[48] Parker, D.: The performance of BAA before and after privatisation: A DEA study. Journal of Transp. Econ. Policy 33, 133-146 (1998).

[49] Pindado, J., de Queiroz, V., de la Torre, C.: How do firm characteristics influence the relationship between R\&D and firm value? Financ. Manage. 39, 757-782 (2010).

[50] Ramanathan, R.: Evaluating the comparative performance of countries of the Middle East and North Africa: A DEA application. Socio-Economic Planning Sciences 40, 156-167 (2006). 
[51] Sarrico, C.S., Dyson, R.G.: Using DEA for planning in UK universities - an institutional perspective. J. Oper. Res. Soc. 51, 789-800 (2000).

[52] Shimura, H. Masuda, S. and Kimura, H.: Research and development productivity map: visualization of industry status. J. Clin. Pharm. Ther. 39, 175-180 (2014).

[53] Simar, L., Wilson, P.W.: Two-stage DEA: caveat emptor. J. Prod. Anal. 36, 205-218 (2011).

[54] The Economist. Clinical trials. Spilling the beans. Failure to publish the results of all clinical trials is skewing medical science. Published in the print edition on July 25, 2015. Available through http://www.economist.com/news/science-and-technology/21659703-failure-publish-results-all-clinicaltrials-skewing-medical (2015).

[55] Thomas, R.R., Bar, R.S., Cron, W.L., Slocum Jr., J.W.: A process for evaluating retail store efficiency: a restricted DEA approach. Int. J. Res. Mark. 15, 487-503 (1998).

[56] Wang, E.C., Huang, W.: Relative efficiency of R\&D activities: A cross-country study accounting for environmental factors in the DEA approach. Res. Policy 36, 260-273 (2007).

[57] Wang, W.K., Lu, W.M., Liu, P.Y.: A fuzzy multi-objective two-stage DEA model for evaluating the performance of US bank holding companies. Expert Syst. Appl. 41, 4290-4297 (2014).

[58] Wanke, P., Barros, C.: Two-stage DEA: An application to major Brazilian banks. Expert Syst. Appl. 41, 2337-2344 (2014).

[59] You, T., Chen, X., Holder, M.E.: Efficiency and its determinants in pharmaceutical industries: ownership, R\&D and scale economy. Appl. Econ. 42, 2217-2241 (2010)

[60] Zhu, J.: Imprecise data envelopment analysis (IDEA): A review and improvement with an application. Eur. J. Oper. Res. 144, 513-529 (2003).

\section{Appendix A}

*******************************************************************************

PLEASE INSERT TABLE A1 ABOUT HERE

PLEASE INSERT TABLE A2 ABOUT HERE

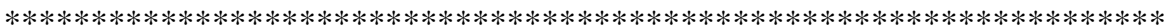

* ${ }^{2} * * * * * * * * * * * * * * * * * * * * * * * * * * * * * * * * * * * * * * * * * * * * * * * * * * * * * * * * * * * * * * * *$

PLEASE INSERT TABLE A3 ABOUT HERE 
*****************************************************************************

\section{Appendix B}

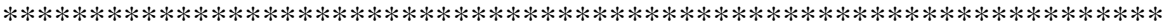

PLEASE INSERT TABLE B1 ABOUT HERE

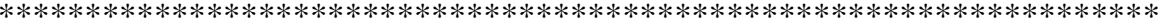

**************************************************************************

PLEASE INSERT TABLE B2 ABOUT HERE

**************************************************************************** 
Drug Portfolio: Strategic issues

1. Efficiency in developing innovative drugs

2. Total Budget $=$ R\&D budget + Financial transactions budget

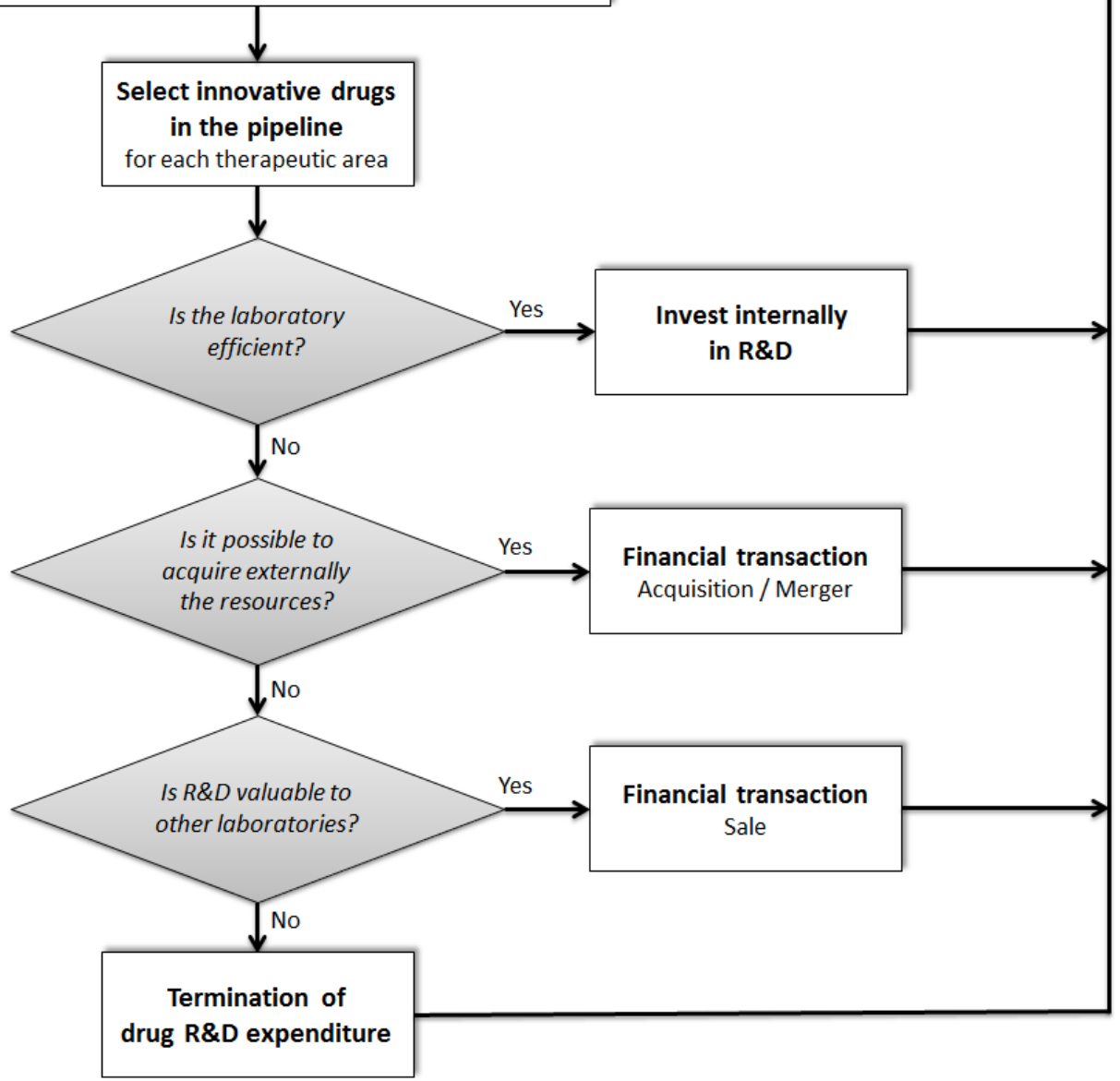

Fig. 1. Internal and external R\&D management of drug portfolio. 


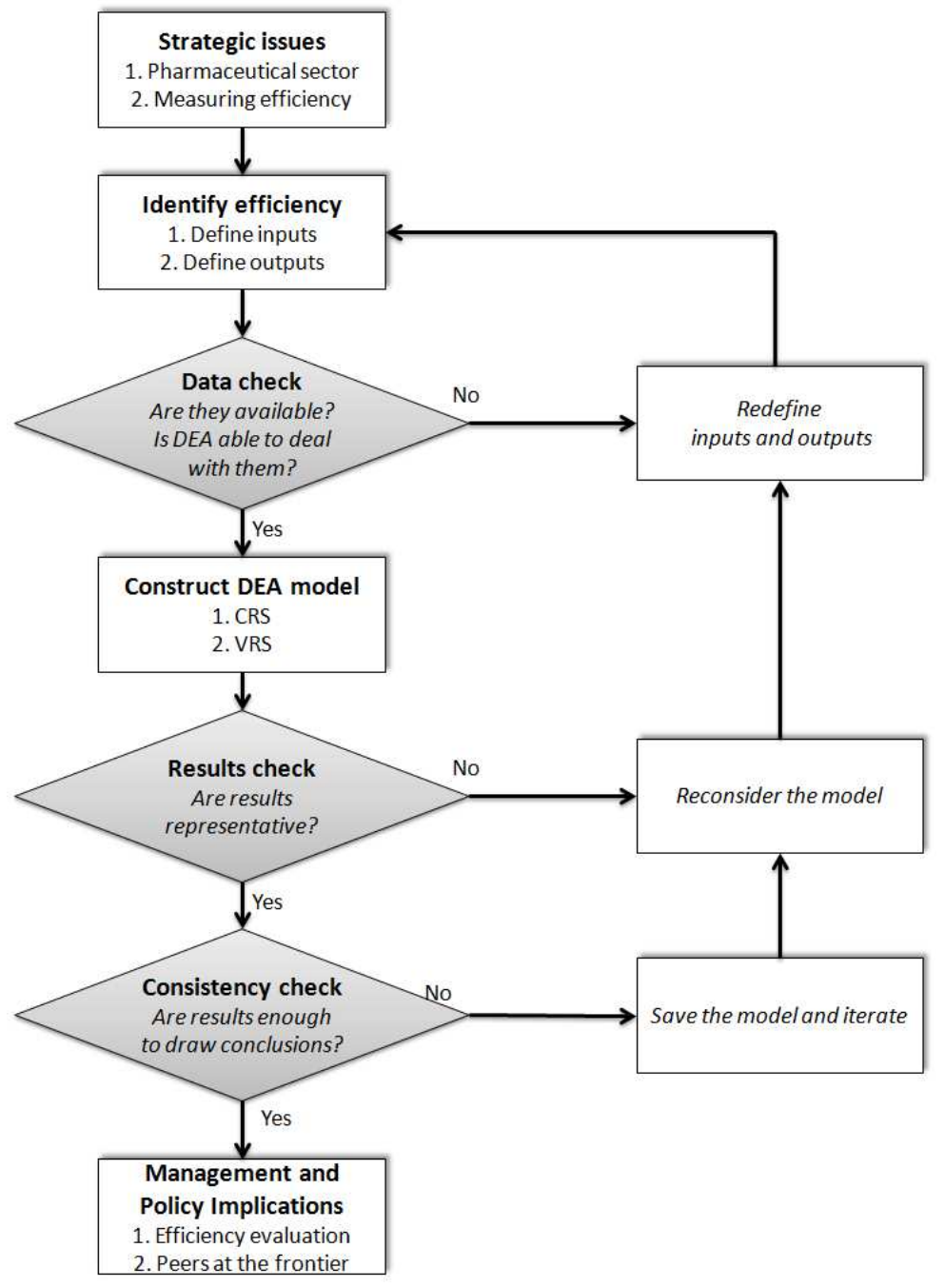

Fig. 2. Evaluation process of the laboratories' efficiency. 

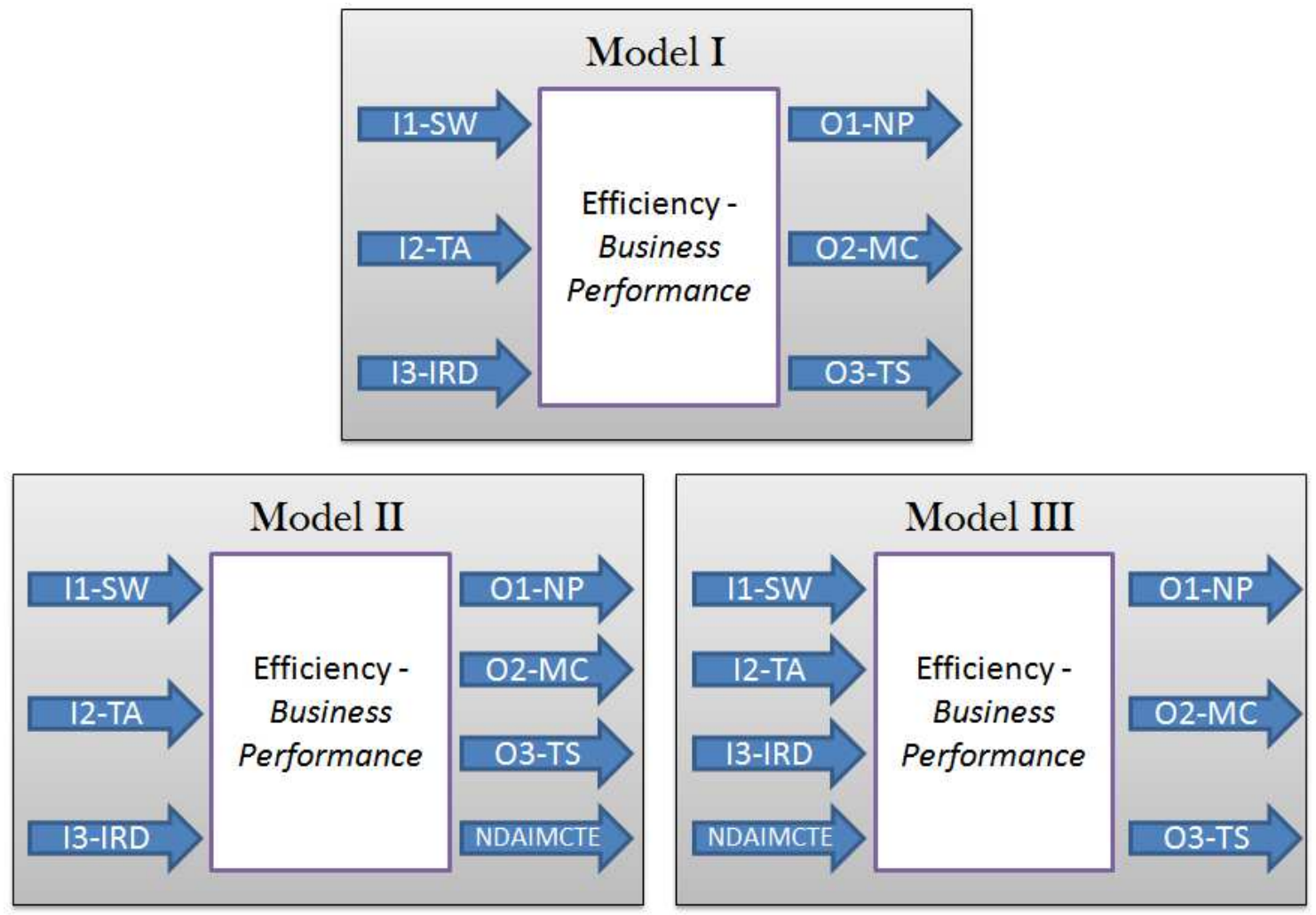

Fig. 3. Overview of the three final models. 
Table 1. Summary statistics for the database

\begin{tabular}{cccccc}
\hline Variable & Unit & Average & Min & Max & St. Dev. \\
\hline I1-SW & employees & $34,788.61$ & 272.5 & $120,300.00$ & $39,910.4$ \\
I2-TA & Million USD & $33,521.3$ & 106.7 & $176,414.2$ & $41,399.7$ \\
I3-IRD & Million USD & $2,601.5$ & 0.6 & $9,092.6$ & $2,743.6$ \\
O1-NP & Million USD & $2,829.2$ & 1.6 & $12,150.8$ & $3,326.9$ \\
O2-MC & Million USD & $44,847.0$ & 136.7 & $190,890.1$ & $49,688.5$ \\
O3-TS & Million USD & $17,506.9$ & 32.7 & $65,151.2$ & $19,208.5$ \\
I4/O4-NDAIMCTE & Days & $7,368.3$ & 111.7 & $43,543.9$ & $9,077.1$ \\
\hline
\end{tabular}


Table 2. Efficiency of the Pharmaceutical Laboratories using DEA (models I, II, and III): VRS assumption

\begin{tabular}{|c|c|c|c|c|c|}
\hline \multirow[b]{2}{*}{ Company } & \multirow{2}{*}{$\begin{array}{c}\text { Model I } \\
\text { Efficiency }\end{array}$} & \multicolumn{2}{|c|}{ Model II } & \multicolumn{2}{|c|}{ Model III } \\
\hline & & Efficiency & $\begin{array}{c}\text { Change } \\
\text { rate }\end{array}$ & Efficiency & $\begin{array}{c}\text { Change } \\
\text { rate }\end{array}$ \\
\hline ABBOTT & $100,00 \%$ & $100,00 \%$ & $0,00 \%$ & $100,00 \%$ & $0,00 \%$ \\
\hline ALLERGAN & $86,30 \%$ & $86,30 \%$ & $0,00 \%$ & $96,30 \%$ & $10,00 \%$ \\
\hline AMGEN & $100,00 \%$ & $100,00 \%$ & $0,00 \%$ & $100,00 \%$ & $0,00 \%$ \\
\hline ASTELLAS & $100,00 \%$ & $100,00 \%$ & $0,00 \%$ & $100,00 \%$ & $0,00 \%$ \\
\hline ASTRAZENECA & $95,20 \%$ & $97,00 \%$ & $1,80 \%$ & $95,20 \%$ & $0,00 \%$ \\
\hline BAYER & $100,00 \%$ & $100,00 \%$ & $0,00 \%$ & $100,00 \%$ & $0,00 \%$ \\
\hline BIOGEN & $88,20 \%$ & $88,20 \%$ & $0,00 \%$ & $100,00 \%$ & $11,80 \%$ \\
\hline BRISTOL & $91,90 \%$ & $95,20 \%$ & $3,30 \%$ & $91,90 \%$ & $0,00 \%$ \\
\hline CELGENE & $100,00 \%$ & $100,00 \%$ & $0,00 \%$ & $100,00 \%$ & $0,00 \%$ \\
\hline CELLTRION & $100,00 \%$ & $100,00 \%$ & $0,00 \%$ & $100,00 \%$ & $0,00 \%$ \\
\hline CSL & $100,00 \%$ & $100,00 \%$ & $0,00 \%$ & $100,00 \%$ & $0,00 \%$ \\
\hline EISAI & $100,00 \%$ & $100,00 \%$ & $0,00 \%$ & $100,00 \%$ & $0,00 \%$ \\
\hline ELI LILLY & $97,60 \%$ & $100,00 \%$ & $2,40 \%$ & $97,60 \%$ & $0,00 \%$ \\
\hline GILEAD & $100,00 \%$ & $100,00 \%$ & $0,00 \%$ & $100,00 \%$ & $0,00 \%$ \\
\hline GLAXOSMITHKLINE & $100,00 \%$ & $100,00 \%$ & $0,00 \%$ & $100,00 \%$ & $0,00 \%$ \\
\hline H. LUNDBECK & $91,10 \%$ & $91,10 \%$ & $0,00 \%$ & $91,20 \%$ & $0,10 \%$ \\
\hline HOSPIRA & $100,00 \%$ & $100,00 \%$ & $0,00 \%$ & $100,00 \%$ & $0,00 \%$ \\
\hline IPSEN & $81,60 \%$ & $81,60 \%$ & $0,00 \%$ & $83,30 \%$ & $1,70 \%$ \\
\hline JOHNSON \& JOHNS. & $100,00 \%$ & $100,00 \%$ & $0,00 \%$ & $100,00 \%$ & $0,00 \%$ \\
\hline MEDA AB & $100,00 \%$ & $100,00 \%$ & $0,00 \%$ & $100,00 \%$ & $0,00 \%$ \\
\hline MEDICINES COMP. & $100,00 \%$ & $100,00 \%$ & $0,00 \%$ & $100,00 \%$ & $0,00 \%$ \\
\hline MERCK (KGAA) & $100,00 \%$ & $100,00 \%$ & $0,00 \%$ & $100,00 \%$ & $0,00 \%$ \\
\hline MERCK \& CO & $82,80 \%$ & $91,50 \%$ & $8,70 \%$ & $82,80 \%$ & $0,00 \%$ \\
\hline MITSUBISHI & $72,10 \%$ & $72,10 \%$ & $0,00 \%$ & $93,60 \%$ & $21,50 \%$ \\
\hline NOVARTIS & $86,80 \%$ & $100,00 \%$ & $13,20 \%$ & $86,80 \%$ & $0,00 \%$ \\
\hline NOVO NORDISK & $100,00 \%$ & $100,00 \%$ & $0,00 \%$ & $100,00 \%$ & $0,00 \%$ \\
\hline ORION & $100,00 \%$ & $100,00 \%$ & $0,00 \%$ & $100,00 \%$ & $0,00 \%$ \\
\hline OTSUKA & $95,10 \%$ & $95,10 \%$ & $0,00 \%$ & $96,30 \%$ & $1,20 \%$ \\
\hline PFIZER & $100,00 \%$ & $100,00 \%$ & $0,00 \%$ & $100,00 \%$ & $0,00 \%$ \\
\hline REGENERON & $100,00 \%$ & $100,00 \%$ & $0,00 \%$ & $100,00 \%$ & $0,00 \%$ \\
\hline RICHTER & $70,20 \%$ & $70,20 \%$ & $0,00 \%$ & $82,60 \%$ & $12,40 \%$ \\
\hline ROCHE & $100,00 \%$ & $100,00 \%$ & $0,00 \%$ & $100,00 \%$ & $0,00 \%$ \\
\hline SANOFI & $75,00 \%$ & $81,60 \%$ & $6,60 \%$ & $75,00 \%$ & $0,00 \%$ \\
\hline SHIRE & $97,60 \%$ & $100,00 \%$ & $2,40 \%$ & $97,60 \%$ & $0,00 \%$ \\
\hline TAKEDA & $93,90 \%$ & $100,00 \%$ & $6,10 \%$ & $93,90 \%$ & $0,00 \%$ \\
\hline TEVA & $100,00 \%$ & $100,00 \%$ & $0,00 \%$ & $100,00 \%$ & $0,00 \%$ \\
\hline UCB & $52,10 \%$ & $75,40 \%$ & $23,30 \%$ & $52,10 \%$ & $0,00 \%$ \\
\hline
\end{tabular}

Note: The 'Change rate' columns show the number of companies whose improvement in efficiency is significant (greater than $5 \%$ ). 
Table 3. Summary of the results for models II, III, and IV under the VRS assumption

\begin{tabular}{c|c|cc|cc}
\hline \multirow{2}{*}{ Company } & Model I & \multicolumn{2}{|c|}{ Model II } & \multicolumn{2}{c}{ Model III } \\
& Efficiency & Efficiency & $\begin{array}{c}\text { Change } \\
\text { rate }\end{array}$ & Efficiency & $\begin{array}{c}\text { Change } \\
\text { rate }\end{array}$ \\
\hline Average & $93.45 \%$ & $95.28 \%$ & $1.83 \%$ & $95.03 \%$ & $1.59 \%$ \\
St Dev & $11.02 \%$ & $8.59 \%$ & $4.64 \%$ & $9.63 \%$ & $4.61 \%$ \\
\hline Efficient firms $(*)$ & 21 & 25 & $(5)$ & 22 & $(4)$ \\
Efficiency: $[85 \%, 100 \%)$ & 10 & 7 & & 10 & \\
Efficiency: $[70 \%, 85 \%)$ & 5 & 5 & & 4 & \\
Efficiency: $[50 \%, 70 \%)$ & 1 & 0 & & 1 & \\
Efficiency: $[0 \%, 50 \%)$ & 0 & 0 & & 0 & \\
\hline
\end{tabular}

Note: The 'Change rate' columns show the number of companies whose improvement in efficiency is significant (greater than 5\%). 
Table 4. Benchmark peers of each pharmaceutical laboratory (models I, II and III): VRS assumption

\begin{tabular}{|c|c|c|c|c|}
\hline Company & Ref. & Model I & Model II & Model III \\
\hline ABBOTT & 1 & 1 & 1 & 1 \\
\hline ALLERGAN & 2 & $6-26-27-14$ & $26-14-6-27$ & $10-7-1-14-26-32$ \\
\hline AMGEN & 3 & 3 & 3 & 3 \\
\hline ASTELLAS & 4 & 4 & 4 & 4 \\
\hline ASTRAZENECA & 5 & $32-26-19-14$ & $32-16-19-14-26$ & $26-32-14-19$ \\
\hline BAYER & 6 & 6 & 6 & 6 \\
\hline BIOGEN & 7 & $26-12-14-21$ & $26-21-12-14$ & 7 \\
\hline BRISTOL & 8 & $14-32-3-19$ & $35-14-15-32-19$ & $14-3-19-32$ \\
\hline CELGENE & 9 & 9 & 9 & 9 \\
\hline CELLTRION & 10 & 10 & 10 & 10 \\
\hline CSL & 11 & 11 & 11 & 11 \\
\hline EISAI & 12 & 12 & 12 & 12 \\
\hline ELI LILLY & 13 & $26-32-19-14$ & 13 & $19-32-26-14$ \\
\hline GILEAD & 14 & 14 & 14 & 14 \\
\hline GLAXOSMITHKLINE & 15 & 15 & 15 & 15 \\
\hline H. LUNDBECK & 16 & $4-26-12-21$ & $4-27-26-12-21$ & $14-26-4-21$ \\
\hline HOSPIRA & 17 & 17 & 17 & 17 \\
\hline IPSEN & 18 & $26-27-21$ & $21-26-27$ & $21-26-10-14$ \\
\hline JOHNSON \& JOHNS. & 19 & 19 & 19 & 19 \\
\hline MEDA AB & 20 & 20 & 20 & 20 \\
\hline MEDICINES COMP. & 21 & 21 & 21 & 21 \\
\hline MERCK (KGAA) & 22 & 22 & 22 & 22 \\
\hline MERCK \& CO & 23 & $32-3-29-19$ & $29-35-25-19$ & $32-3-19-29$ \\
\hline MITSUBISHI & 24 & $6-14-26-27$ & $26-14-6-27$ & $1-7-10-32$ \\
\hline NOVARTIS & 25 & 14-19 & 25 & 14-19 \\
\hline NOVO NORDISK & 26 & 26 & 26 & 26 \\
\hline ORION & 27 & 27 & 27 & 27 \\
\hline OTSUKA & 28 & $14-32-26-6$ & $14-32-6-26$ & $26-14-10-6-32$ \\
\hline PFIZER & 29 & 29 & 29 & 29 \\
\hline REGENERON & 30 & 30 & 30 & 30 \\
\hline RICHTER & 31 & $11-17-20-22$ & $11-20-22-17$ & $1-17-10-36-11$ \\
\hline ROCHE & 32 & 32 & 32 & 32 \\
\hline SANOFI & 33 & 6-19-14 & $15-36-6-19$ & 14-6-19 \\
\hline SHIRE & 34 & $14-12-26-21$ & 34 & $14-12-26-21$ \\
\hline TAKEDA & 35 & $14-3-32$ & 35 & 32-14-3 \\
\hline TEVA & 36 & 36 & 36 & 36 \\
\hline $\mathbf{U C B}$ & 37 & $6-14-26-27$ & $25-34$ & $26-6-27-14$ \\
\hline
\end{tabular}


Table 5. Transactions per year in the sample of 37 pharmaceutical laboratories

\begin{tabular}{c|c|c}
\hline Company & $\begin{array}{c}\text { Number of announced } \\
\text { transactions }\end{array}$ & $\begin{array}{c}\text { Total } \\
\text { accumulated size }\end{array}$ \\
\hline $\mathbf{2 0 0 8}$ & 346 & $154,762.56$ \\
$\mathbf{2 0 0 9}$ & 335 & $211,270.56$ \\
$\mathbf{2 0 1 0}$ & 338 & $159,756.12$ \\
$\mathbf{2 0 1 1}$ & 339 & $218,567.56$ \\
$\mathbf{2 0 1 2}$ & 369 & $106,518.07$ \\
$\mathbf{2 0 1 3}$ & 344 & $131,421.59$ \\
\hline OVERALL & 2,071 & $982,296.46$ \\
\hline
\end{tabular}


Table 6. Transactions per pharmaceutical laboratory in the period 2008-2013

\begin{tabular}{|c|c|c|}
\hline Company & $\begin{array}{c}\text { Number of announced } \\
\text { transactions }\end{array}$ & $\begin{array}{c}\text { Total } \\
\text { accumulated size }\end{array}$ \\
\hline ABBOTT & 39 & $80,697.08$ \\
\hline ALLERGAN & 20 & $3,032.35$ \\
\hline AMGEN & 42 & $38,462.54$ \\
\hline ASTELLAS & 47 & $8,434.67$ \\
\hline ASTRAZENECA & 53 & $31,058.81$ \\
\hline BAYER & 87 & $9,978.34$ \\
\hline BIOGEN & 32 & $7,735.07$ \\
\hline BRISTOL & 26 & $43,903.35$ \\
\hline CELGENE & 43 & $23,724.35$ \\
\hline CELLTRION & 8 & 156.41 \\
\hline CSL & 0 & 0 \\
\hline EISAI & 12 & 406.54 \\
\hline ELI LILLY & 64 & $25,353.78$ \\
\hline GILEAD & 14 & $28,020.47$ \\
\hline GLAXOSMITHKLINE & 156 & $29,984.79$ \\
\hline H. LUNDBECK & 18 & $1,767.05$ \\
\hline HOSPIRA & 11 & $1,129.29$ \\
\hline IPSEN & 24 & $4,743.54$ \\
\hline JOHNSON \& JOHNS. & 168 & $64,503.65$ \\
\hline MEDA AB & 28 & $2,341.58$ \\
\hline MEDICINES COMP. & 10 & $1,909.29$ \\
\hline MERCK (KGAA) & 58 & $19,057.58$ \\
\hline MERCK \& CO & 74 & $79,208.71$ \\
\hline MITSUBISHI & 365 & $42,644.27$ \\
\hline NOVARTIS & 158 & $83,839.67$ \\
\hline NOVO NORDISK & 28 & $11,698.79$ \\
\hline ORION & 5 & 459.63 \\
\hline OTSUKA & 4 & 260.19 \\
\hline PFIZER & 112 & $159,115.88$ \\
\hline REGENERON & 4 & 75.53 \\
\hline RICHTER & 22 & $1,104.19$ \\
\hline ROCHE & 83 & $64,088.58$ \\
\hline SANOFI & 87 & $43,349.41$ \\
\hline SHIRE & 35 & $8,547.54$ \\
\hline TAKEDA & 48 & $28,933.18$ \\
\hline TEVA & 70 & $30,793.83$ \\
\hline UCB & 16 & $1,776.53$ \\
\hline OVERALL & 2,071 & $982,296.46$ \\
\hline
\end{tabular}


Table 7. Summary of the results of the regression models

\begin{tabular}{ccccc} 
Explanatory variables & OLS 1 & OLS 2 & OLS 3 & OLS 4 \\
\hline R\&D / Total Assets & $5.528^{* * *}$ & $6.275^{* * *}$ & $41.541 * *$ & $10.010^{* * *}$ \\
DEA Efficiency & $(1.162)$ & $(1.239)$ & $(16.272)$ & $(1.915)$ \\
& $1.107 * * *$ & & $4.149 * * *$ & \\
DEA Efficiency Dummy & $(0.320)$ & & $(1.207)$ & \\
R\&D / Total Assets * & & $0.255^{* *}$ & & $0.777 * * *$ \\
DEA Efficiency & & $(0.101)$ & & $(0.196)$ \\
R\&D / Total Assets * & & & $-37.464 * *$ & \\
DEA Efficiency Dummy & & & $(16.921)$ & \\
Constant & $-0.690 * *$ & 0.134 & $-3.620 * * *$ & -0.263 \\
R-squared & $(0.289)$ & $(0.125)$ & $(1.169)$ & $(0.168)$ \\
\hline Number of observations & 0.159 & 0.163 & 0.190 & 0.183 \\
\hline
\end{tabular}

Note: *,**,*** indicate significance at the 1,5 and $10 \%$ level. Robust standard errors in parentheses. 
Table A1. Datastream output measures. 37 laboratories versus 241 laboratories (data in million USD)

\begin{tabular}{|c|c|c|c|c|c|c|c|}
\hline Output & $\begin{array}{c}\text { Number of } \\
\text { pharma labs }\end{array}$ & 2008 & 2009 & 2010 & 2011 & 2012 & Sum 2013 \\
\hline 01-NP & 37 & 87,018 & 113,048 & 100,980 & 109,562 & 107,580 & 108,967 \\
\hline O1-NP & 241 & 93,279 & 121,845 & 115,168 & 125,961 & 124,379 & 123,492 \\
\hline Percentage & - & $93.3 \%$ & $92.8 \%$ & $87.7 \%$ & $87.0 \%$ & $86.5 \%$ & $88.2 \%$ \\
\hline O2-MC & 37 & $1,316,178$ & $1,497,453$ & $1,479,184$ & $1,591,657$ & $1,797,990$ & $2,242,927$ \\
\hline O2-MC & 241 & $1,465,046$ & $1,693,558$ & $1,742,159$ & $1,856,308$ & $2,181,790$ & $2,823,773$ \\
\hline Percentage & - & $89.8 \%$ & $88.4 \%$ & $84.9 \%$ & $85.7 \%$ & $82.4 \%$ & $79.4 \%$ \\
\hline O3-TS & 37 & 543,044 & 602,776 & 673,175 & 685,712 & 692,554 & 676,711 \\
\hline O3-TS & 241 & 628,929 & 721,607 & 820,815 & 856,171 & 883,483 & 867,525 \\
\hline Percentage & - & $86.3 \%$ & $83.5 \%$ & $82.0 \%$ & $80.1 \%$ & $78.4 \%$ & $78.0 \%$ \\
\hline
\end{tabular}


Table A2. New drugs authorized by EMA and FDA in the period 2008 to 2013 without the effect of M\&A

\begin{tabular}{|c|c|c|c|c|}
\hline Agency & Year & Number of Authorized Drugs & Number of Days & Number of Days Discounted \\
\hline EMA & 2008 & 38 & 72,209 & 67,676 \\
\hline EMA & 2009 & 44 & 70,465 & 66,915 \\
\hline EMA & 2010 & 22 & 25,205 & 24,229 \\
\hline EMA & 2011 & 38 & 32,876 & 32,005 \\
\hline EMA & 2012 & 22 & 11,252 & 11,082 \\
\hline EMA & 2013 & 43 & 7,135 & 7,088 \\
\hline FDA & 2008 & 10 & 19,759 & 18,504 \\
\hline FDA & 2009 & 12 & 19,847 & 18,819 \\
\hline FDA & 2010 & 7 & 9,116 & 8,753 \\
\hline FDA & 2011 & 14 & 12,969 & 12,611 \\
\hline FDA & 2012 & 17 & 8,430 & 8,304 \\
\hline FDA & 2013 & 14 & 2,430 & 2,413 \\
\hline EMA + FDA & 2008 & 48 & 91,968 & 86,180 \\
\hline EMA + FDA & 2009 & 56 & 90,312 & 85,734 \\
\hline EMA + FDA & 2010 & 29 & 34,321 & 32,982 \\
\hline EMA + FDA & 2011 & 52 & 45,845 & 44,616 \\
\hline EMA + FDA & 2012 & 39 & 19,682 & 19,386 \\
\hline EMA + FDA & 2013 & 57 & 9,565 & 9,502 \\
\hline
\end{tabular}


Table A3. New drugs authorized by EMA and FDA in the period 2008 to 2013 belonging to M\&A

\begin{tabular}{|c|c|c|c|c|}
\hline Agency & Year & Number of Authorized Drugs & Number of Days & Number of Days Discounted \\
\hline EMA & 2008 & 1 & 1,862 & 1,752 \\
\hline EMA & 2009 & 2 & 3,279 & 3,111 \\
\hline EMA & 2010 & 0 & 0 & 0 \\
\hline EMA & 2011 & 0 & 0 & 0 \\
\hline EMA & 2012 & 0 & 0 & 0 \\
\hline EMA & 2013 & 1 & 110 & 110 \\
\hline FDA & 2008 & 1 & 2,132 & 1,985 \\
\hline FDA & 2009 & 0 & 0 & 0 \\
\hline FDA & 2010 & 1 & 1,453 & 1,388 \\
\hline FDA & 2011 & 0 & 0 & 0 \\
\hline FDA & 2012 & 3 & 1,755 & 1,725 \\
\hline FDA & 2013 & 2 & 401 & 398 \\
\hline EMA + FDA & 2008 & 2 & 3,994 & 3,736 \\
\hline EMA + FDA & 2009 & 2 & 3,279 & 3,111 \\
\hline EMA + FDA & 2010 & 1 & 1,453 & 1,388 \\
\hline EMA + FDA & 2011 & 0 & 0 & 0 \\
\hline EMA + FDA & 2012 & 3 & 1,755 & 1,725 \\
\hline EMA + FDA & 2013 & 3 & 511 & 508 \\
\hline
\end{tabular}


Table B1. Outputs for the DEA model

\begin{tabular}{|c|c|c|c|c|c|}
\hline Company & Ref. & $\begin{array}{c}\text { O1 - NP }(*) \\
\text { Net Income Basic }\end{array}$ & $\begin{array}{c}\mathrm{O} 2-\mathrm{MC}(*) \\
\text { Market Capitalization }\end{array}$ & $\begin{array}{c}\text { O3-TS }(*) \\
\text { Net Sales }\end{array}$ & $\begin{array}{c}\text { O4 - NDAIMCTE }(*) \\
\text { Number of days } \\
\text { discounted until } \\
\text { December } 13\end{array}$ \\
\hline ABBOTT & 1 & $4,728,933$ & 81,795 & $32,672,025$ & 127 \\
\hline ALLERGAN & 2 & 703,150 & 23,442 & $5,225,333$ & 1,205 \\
\hline AMGEN & 3 & $4,422,833$ & 63,146 & $16,029,000$ & 6,921 \\
\hline ASTELLAS & 4 & $1,312,290$ & 20,471 & $11,049,964$ & 6,924 \\
\hline ASTRAZENECA & 5 & $6,535,839$ & 64,026 & $29,901,216$ & 9,045 \\
\hline BAYER & 6 & $2,843,425$ & 69,912 & $48,787,267$ & 7,291 \\
\hline BIOGEN & 7 & $1,204,907$ & 28,791 & $5,121,517$ & 1,148 \\
\hline BRISTOL & 8 & $3,006,000$ & 55,933 & $19,023,167$ & 6,972 \\
\hline CELGENE & 9 & 724,639 & 35,263 & $4,233,646$ & 6,347 \\
\hline CELLTRION & 10 & 1,560 & 137 & 32,695 & 112 \\
\hline CSL & 11 & 941,535 & 21,068 & $4,072,829$ & 3,040 \\
\hline EISAI & 12 & 472,294 & 11,645 & $8,224,303$ & 7,081 \\
\hline ELI LILLY & 13 & $3,407,917$ & 48,338 & $22,548,833$ & 7,129 \\
\hline GILEAD & 14 & $2,669,696$ & 52,759 & $8,263,849$ & 3,113 \\
\hline GLAXOSMITHKLINE & 15 & $7,117,737$ & 109,774 & $42,449,777$ & 28,802 \\
\hline H. LUNDBECK & 16 & 310,826 & 3,818 & $2,607,541$ & 2,614 \\
\hline HOSPIRA & 17 & 184,750 & 6,478 & $3,929,667$ & 1,362 \\
\hline IPSEN & 18 & 121,484 & 3,282 & $1,543,927$ & 1,616 \\
\hline JOHNSON \& JOHNS. & 19 & $12,150,833$ & 190,890 & $65,151,167$ & 14,429 \\
\hline MEDA AB & 20 & 183,033 & 2,858 & $1,805,137$ & 2,283 \\
\hline MEDICINES COMP. & 21 & 35,758 & 1,122 & 486,871 & 1,853 \\
\hline MERCK (KGAA) & 22 & 12,745 & 185 & 108,256 & 936 \\
\hline MERCK \& CO & 23 & $6,391,050$ & 112,088 & $39,450,600$ & 24,469 \\
\hline
\end{tabular}




\begin{tabular}{|c|c|c|c|c|c|}
\hline MITSUBISHI & 24 & 373,502 & 8,144 & $4,491,237$ & 341 \\
\hline NOVARTIS & 25 & $9,307,241$ & 162,456 & $53,173,503$ & 43,544 \\
\hline NOVO NORDISK & 26 & $2,982,551$ & 54,037 & $11,684,809$ & 4,140 \\
\hline ORION & 27 & 247,665 & 1,056 & $1,184,442$ & 2,549 \\
\hline OTSUKA & 28 & 924,146 & 15,321 & $12,549,824$ & 3,174 \\
\hline PFIZER & 29 & $9,172,833$ & 159,328 & $57,351,500$ & 13,270 \\
\hline REGENERON & 30 & 116,311 & 9,003 & 834,308 & 3,810 \\
\hline RICHTER & 31 & 237,170 & 3,387 & $1,392,848$ & 664 \\
\hline ROCHE & 32 & $9,703,329$ & 30,595 & $48,172,073$ & 5,838 \\
\hline SANOFI & 33 & $6,550,360$ & 105,872 & $42,740,575$ & 17,114 \\
\hline SHIRE & 34 & 586,697 & 16,201 & $3,844,582$ & 6,694 \\
\hline TAKEDA & 35 & $2,669,367$ & 36,543 & $16,746,817$ & 19,833 \\
\hline TEVA & 36 & $2,015,502$ & 41,540 & $16,822,439$ & 6,186 \\
\hline UCB & 37 & 310,067 & 8,635 & $4,046,009$ & 6,149 \\
\hline
\end{tabular}

* Datastream Data is in thousand USD for Net Income Basic and Net Sales, while market cap is in million USD.

** The number of days discounted is computed for each pharmaceutical laboratory until December 2013. M\&A activity only affected two pharmaceutical laboratories with authorized drugs in the period 2008 to 2013 (Pfizer and Roche). 
Table B2. Inputs for the DEA model

\begin{tabular}{|c|c|c|c|c|c|}
\hline Company & Ref. & $\begin{array}{c}\text { I1 - SW (*) } \\
\text { Employees }\end{array}$ & $\begin{array}{c}\text { I2-TA }(*) \\
\text { Total Assets }\end{array}$ & $\begin{array}{c}\text { I3 - IRD (*) } \\
\text { Investment in R\&D }\end{array}$ & $\begin{array}{c}4 \text { - NDAIMCTE }(* *) \\
\text { Number of days } \\
\text { discounted until } \\
\text { December } 13\end{array}$ \\
\hline ABBOTT & 1 & 80,500 & $52,395,697$ & $3,153,094$ & 127 \\
\hline ALLERGAN & 2 & 9,740 & $8,365,350$ & 842,350 & 1,205 \\
\hline AMGEN & 3 & 17,883 & $48,142,000$ & $3,234,833$ & 6,921 \\
\hline ASTELLAS & 4 & 15,651 & $15,273,737$ & $2,059,089$ & 6,924 \\
\hline ASTRAZENECA & 5 & 58,200 & $52,071,173$ & $4,231,109$ & 9,045 \\
\hline BAYER & 6 & 110,650 & $68,614,409$ & $3,982,957$ & 7,291 \\
\hline BIOGEN & 7 & 5,350 & $9,361,089$ & $1,267,042$ & 1,148 \\
\hline BRISTOL & 8 & 28,833 & $32,178,833$ & $3,507,500$ & 6,972 \\
\hline CELGENE & 9 & 3,949 & $9,113,421$ & $1,309,492$ & 6,347 \\
\hline CELLTRION & 10 & 273 & 186,354 & 975 & 112 \\
\hline CSL & 11 & 10,303 & $5,279,541$ & 306,281 & 3,040 \\
\hline EISAI & 12 & 10,977 & $11,545,267$ & $1,808,208$ & 7,081 \\
\hline ELI LILLY & 13 & 38,928 & $31,830,383$ & $4,813,633$ & 7,129 \\
\hline GILEAD & 14 & 4,159 & $14,730,257$ & $1,291,045$ & 3,113 \\
\hline GLAXOSMITHKLINE & 15 & 98,679 & $61,559,984$ & $5,668,148$ & 28,802 \\
\hline H. LUNDBECK & 16 & 5,582 & $3,400,398$ & 503,502 & 2,614 \\
\hline HOSPIRA & 17 & 15,000 & $5,582,733$ & 269,217 & 1,362 \\
\hline IPSEN & 18 & 4,518 & $1,953,324$ & 306,635 & 1,616 \\
\hline JOHNSON \& JOHNS. & 19 & 120,300 & $103,129,833$ & $7,470,000$ & 14,429 \\
\hline MEDA AB & 20 & 2,769 & $5,071,538$ & 92,668 & 2,283 \\
\hline MEDICINES COMP. & 21 & 478 & 742,416 & 111,289 & 1,853 \\
\hline MERCK (KGAA) & 22 & 1,267 & 106,656 & 640 & 936 \\
\hline MERCK \& CO & 23 & 82,367 & $96,384,650$ & $6,901,817$ & 24,469 \\
\hline
\end{tabular}




\begin{tabular}{|c|c|c|c|c|c|}
\hline MITSUBISHI & 24 & 9,478 & $9,188,473$ & 794,988 & 341 \\
\hline NOVARTIS & 25 & 117,179 & $107,311,781$ & $8,699,227$ & 43,544 \\
\hline NOVO NORDISK & 26 & 31,633 & $10,737,626$ & $1,647,363$ & 4,140 \\
\hline ORION & 27 & 3,320 & $1,075,103$ & 122,836 & 2,549 \\
\hline OTSUKA & 28 & 24,526 & $17,422,894$ & $1,828,382$ & 3,174 \\
\hline PFIZER & 29 & 96,967 & $176,414,167$ & $7,828,500$ & 13,270 \\
\hline REGENERON & 30 & 1,556 & $1,405,310$ & 143,325 & 3,810 \\
\hline RICHTER & 31 & 9,315 & $2,719,582$ & 140,159 & 664 \\
\hline ROCHE & 32 & 81,886 & $65,889,688$ & $9,092,583$ & 5,838 \\
\hline SANOFI & 33 & 107,079 & $115,924,165$ & $6,339,443$ & 17,114 \\
\hline SHIRE & 34 & 4,631 & $5,896,458$ & 743,059 & 6,694 \\
\hline TAKEDA & 35 & 22,336 & $35,046,990$ & $3,610,550$ & 19,833 \\
\hline TEVA & 36 & 41,617 & $41,970,743$ & $1,075,776$ & 6,186 \\
\hline UCB & 37 & 9,300 & $12,265,666$ & $1,057,417$ & 6,149 \\
\hline
\end{tabular}

* Datastream Data is in thousand USD for Total Assets and Investment in R\&D, and for the other input is in number of employees.

** Note this variable is used as both an input and an output. Again, the number of days discounted is computed for each pharmaceutical laboratory until December 2013. M\&A activity only affected two pharmaceutical laboratories with authorized drugs in the period 2008 to 2013 (Pfizer and Roche). 